\title{
Unveiling the Si cycle using isotopes in an iron-fertilized zone of the Southern Ocean: from mixed-layer supply to export
}

\author{
Ivia Closset ${ }^{1}$, Damien Cardinal ${ }^{1}$, Mathieu Rembauville ${ }^{2}$, François Thil $^{3}$, and Stéphane Blain ${ }^{2}$ \\ ${ }^{1}$ Sorbonne Universités (UPMC, Univ Paris 06)-CNRS-IRD-MNHN, LOCEAN Laboratory, 4 place Jussieu, \\ 75005 Paris, France \\ ${ }^{2}$ Sorbonne Universités (UPMC, Univ Paris 06)-CNRS, Laboratoire d'Océanographie Microbienne (LOMIC), \\ Observatoire Océanologique, 66650 Banyuls/mer, France \\ ${ }^{3}$ Laboratoire des Sciences du Climat et de l'Environnement, CNRS 91190 Gif-sur-Yvette, France \\ Correspondence to: Ivia Closset (ivia.closset@locean-ipsl.upmc.fr)
}

Received: 1 June 2016 - Published in Biogeosciences Discuss.: 8 June 2016

Revised: 14 September 2016 - Accepted: 28 September 2016 - Published: 3 November 2016

\begin{abstract}
A massive diatom bloom forms annually in the surface waters of the naturally iron-fertilized Kerguelen Plateau (Southern Ocean). In this study, silicon isotopic signatures $\left(\delta^{30} \mathrm{Si}\right)$ of silicic acid (DSi) and suspended biogenic silica (BSi) were investigated through the whole water column with unprecedented spatial resolution, during the KEOPS-2 experiment (spring 2011). We used $\delta^{30} \mathrm{Si}$ measurements to track the sources of silicon that fuelled the bloom, and investigated the seasonal evolution of the Si biogeochemical cycle in the iron-fertilized area. We compared the results from stations with various degrees of iron enrichment and bloom conditions to an HNLC reference station. Dissolved and particulate $\delta^{30} \mathrm{Si}$ signatures were highly variable in the upper $500 \mathrm{~m}$, reflecting the effect of intense silicon utilization in spring, while they were quite homogeneous in deeper waters. The Si isotopic and mass balance identified a unique Winter Water (WW) Si source for the iron-fertilized area that originated from southeast of the Kerguelen Plateau and spread northward. When the WW reached a retroflection of the Polar Front (PF), the $\delta^{30} \mathrm{Si}$ composition of the silicic acid pool became progressively heavier. This would result from sequential diapycnal and isopycnal mixings between the initial WW and ML water masses, highlighting the strong circulation of surface waters that defined this zone. When comparing the results from the two KEOPS expeditions, the relationship between DSi depletion, BSi production, and their isotopic composition appears decoupled in the iron-fertilized area. This seasonal decoupling could help to explain the low apparent fractionation factor observed in the
\end{abstract}

ML at the end of summer. Taking into account these considerations, we refined the seasonal net $\mathrm{BSi}$ production in the ML of the iron-fertilized area to $3.0 \pm 0.3 \mathrm{~mol} \mathrm{Si} \mathrm{m}^{-2} \mathrm{yr}^{-1}$, which was exclusively sustained by surface water phytoplankton populations. These insights confirm that the isotopic composition of dissolved and particulate silicon is a promising tool to improve our understanding of the Si biogeochemical cycle since the isotopic and mass balance allows resolution of processes in the Si cycle (i.e. uptake, dissolution, mixing).

\section{Introduction}

The Southern Ocean plays a crucial role in the regulation of the global climate as it contributes significantly to the world's ocean primary production and represents a major carbon sink (Takahashi et al., 2009). In the Southern Ocean, diatoms, a phytoplankton group that produces an opaline cell wall called a frustule (amorphous $\mathrm{SiO}_{2} \mathrm{nH}_{2} \mathrm{O}$ ), are responsible for more than $75 \%$ of the annual primary production. Diatoms are especially dominant in the area south of the Antarctic Polar Front (PF) where they form massive blooms (e.g. Brzezinski et al., 2001). These blooms are often associated with high export events when diatoms are removed from the mixed layer (ML) via aggregation, settling, or grazing processes (Boyd and Trull, 2007; Buesseler, 1998), and thus contribute to the extensive biogenic silica (hereafter referred to as BSi) deposition that characterizes the sediments of this region known 
as the "opal belt" (Tréguer and De la Rocha, 2013; Ragueneau et al., 2000).

Since diatoms preferentially take up light silicon isotopes $\left({ }^{28} \mathrm{Si}\right)$, their biological activity leaves a clear imprint on the isotopic composition of both silicic acid $\left(\mathrm{H}_{4} \mathrm{SiO}_{4}\right.$, hereafter referred to as DSi) and BSi, enriching the DSi pool with the heavy ${ }^{30} \mathrm{Si}$ isotope (De la Rocha et al., 1997). While a recent in vitro study has pointed out that this preferential uptake may vary among diatom species (ranging from -0.54 to $-2.09 \%$, Sutton et al., 2013), field studies have reported a constant $\mathrm{Si}$ isotopic fractionation factor $\left({ }^{30} \varepsilon\right)$ for the Antarctic Circumpolar Current, ACC (e.g. De la Rocha et al., 2000; Cardinal et al., 2005), estimated to $-1.2 \pm 0.2 \%$ on average (Fripiat et al., 2011a). In the reverse reaction, it is not clear whether BSi dissolution fractionates silicon isotopes. Two studies based on laboratory experiments provide contradictory results. Wetzel et al. (2014) performed alkaline digestion of diatom opal in sediment cores and reported no preferential release of a given isotope. Conversely, Demarest et al. (2009) placed fresh siliceous particles in undersaturated seawater and reported a fractionation factor of $-0.55 \% \circ$ associated with the dissolution process. The fractionation of dissolution opposes the one occurring during Si uptake (BSi dissolution preferentially releases ${ }^{28} \mathrm{Si}$ ) which would reduce the overall (or net) fractionation factor. Thus, information on the silicon isotopic composition $\left(\delta^{30} \mathrm{Si}\right)$ potentially enables to identify DSi sources, and discriminate and quantify different processes such as Si uptake, BSi dissolution, or physical mixing (e.g. Fripiat et al., 2011a).

Diatoms generate the largest latitudinal gradient of DSi in the world in the Southern Ocean because of their absolute requirement for silicic acid, from replete conditions south of the PF, in the Antarctic Zone (AZ), to depleted conditions in the Sub-Antarctic Zone (SAZ; e.g. Brzezinski et al., 2001; Sarmiento et al., 2004). This contrasts strongly with the high nutrient low chlorophyll (HNLC) characteristics of the Southern Ocean, which could be more specifically defined as a high nitrate low silicon low chlorophyll area (HNLSiLC, Dugdale et al., 1995). Several studies based on in vitro and artificial $\mathrm{Fe}$ enrichments have shown that $\mathrm{Fe}$ stress is partly responsible for the HNLSiLC status of the ACC (see the review in De Baar et al., 2005; Boyd et al., 2007). In parallel, several field studies have investigated the effect of natural iron delivery on the biogeochemical cycles (e.g. Blain et al., 2007; Pollard et al., 2009).

The KEOPS project consisted of two expeditions (late summer 2005 and early spring 2011) conducted in a naturally iron-fertilized area in the vicinity of the Kerguelen Plateau where a massive phytoplankton bloom is observed annually (Mongin et al., 2008). The first KEOPS expedition (January-February 2005) has highlighted that this bloom is sustained by iron supply originating from iron-rich deep waters through winter mixing and vertical diffusion in summer (Blain et al., 2007). The second expedition also revealed that episodic deepening of the mixed layer (ML) could also con- tribute to the vertical supply of Fe (Bowie et al., 2015). Silicon isotopes studied during the first cruise highlighted important aspects of the Si biogeochemical cycle in both the HNLC and the fertilized area (Fripiat et al., 2011a). It was suggested that the decline of the bloom was strongly controlled by silicic acid and iron co-limitations (Mosseri et al., 2008). Results from KEOPS-2 (October-November 2011) have shown that the Kerguelen bloom was characterized by a complex and heterogeneous distribution of phytoplankton communities (e.g. Lasbleiz et al., 2014), constrained by a mosaic of biogeochemical conditions (Park et al., 2014).

Isotopic variations induced by biological $\mathrm{Si}$ utilization in the Southern Ocean ML can be described in a first approximation using two different models for closed and open systems. In the closed system (also referred to as the Rayleigh model) the surface ocean is considered to have a finite pool of DSi that is not replenished by any external sources. In this case, the reaction progresses in a sequential mode over time: the initial substrate (here silicic acid) is consumed in the $\mathrm{ML}$, which exponentially increases the $\delta^{30} \mathrm{Si}$ of the remaining substrate (Eq. 1). The isotopic composition of the shortterm or instantaneous product (here exported BSi, Eq. 2) differs from the long-term product that accumulates (here BSi in the ML) which holds the same signature as the initial substrate when everything is consumed in the system (Eq. 3):

$$
\begin{aligned}
\delta^{30} \mathrm{Si}_{\text {sub }} & =\delta^{30} \mathrm{Si}_{\text {init }}-{ }^{30} \varepsilon \ln (1-f), \\
\delta^{30} \mathrm{Si}_{\text {inst }} & =\delta^{30} \mathrm{Si}_{\text {sub }}+{ }^{30} \varepsilon, \\
\delta^{30} \mathrm{Si}_{\text {acc }} & =\delta^{30} \mathrm{Si}_{\text {init }}-{ }^{30} \varepsilon\left(\frac{f \times \ln f}{1-f}\right),
\end{aligned}
$$

where ${ }^{30} \varepsilon$ is the isotopic fractionation factor of the reaction, $\mathrm{f}$ is the fraction of the remaining substrate, and the subscripts "sub", "init", "acc", and "inst" refer to the remaining substrate, the initial substrate, the accumulated product, and the instantaneous product respectively.

A distinct system is an open, flow-through system (also referred to as a steady-state model) where a continuous supply of substrate balances the export of product. In this model, the DSi supply equals the sum of the BSi produced and immediately exported and the residual DSi stock leaving the system. Only one product forms from substrate and both $\delta^{30} \mathrm{Si}_{\mathrm{DSi}}$ and $\delta^{30} \mathrm{Si}_{\mathrm{BSi}}$ signatures display linear changes (Eqs. 4 and 5):

$$
\begin{aligned}
\delta^{30} \mathrm{Si}_{\text {sub }} & =\delta^{30} \mathrm{Si}_{\text {init }}-{ }^{30} \varepsilon(1-f), \\
\delta^{30} \mathrm{Si}_{\text {prod }} & =\delta^{30} \mathrm{Si}_{\text {init }}+{ }^{30} \varepsilon \times f .
\end{aligned}
$$

In these two ideal situations, the $\Delta^{30} \mathrm{Si}$, i.e. the difference between $\delta^{30} \mathrm{Si}_{\mathrm{DSi}}$ and $\delta^{30} \mathrm{Si}_{\mathrm{BSi}}$, is considered constant. However, in the ocean, it could actually be altered by processes such as water mixing and BSi dissolution that would affect the isotopic and mass balance (e.g. Demarest et al., 2009). It is likely that natural environments reflect a combination of these closed and open systems, with the real fractionation 
Table 1. Characteristics of the stations sampled during KEOPS-2 and discussed in this study. MLD represents the mixed-layer depth (from Park et al., 2014).

\begin{tabular}{|c|c|c|c|c|c|}
\hline \multirow[b]{2}{*}{ Station } & \multirow[b]{2}{*}{ Zone } & \multicolumn{2}{|c|}{ Position } & \multirow[b]{2}{*}{ Date } & \multirow[b]{2}{*}{$\begin{array}{r}\text { MLD } \\
(\mathrm{m})\end{array}$} \\
\hline & & Latitude & Longitude & & \\
\hline A3-1 & Plateau & $50^{\circ} 37.77^{\prime} \mathrm{S}$ & $72^{\circ} 04.82^{\prime} \mathrm{E}$ & $20 \mathrm{Oct}$ & 160 \\
\hline TNS6 & Meander & $48^{\circ} 46.78^{\prime} \mathrm{S}$ & $72^{\circ} 16.77^{\prime} \mathrm{E}$ & $22 \mathrm{Oct}$ & 67 \\
\hline $\mathrm{R} 2$ & HNLC & $50^{\circ} 21.52^{\prime} \mathrm{S}$ & $66^{\circ} 43.00^{\prime} \mathrm{E}$ & $26 \mathrm{Oct}$ & 110 \\
\hline E1 & Meander & $48^{\circ} 29.88^{\prime} \mathrm{S}$ & $72^{\circ} 10.66^{\prime} \mathrm{E}$ & 30 Oct & 66 \\
\hline E2 & Meander & $48^{\circ} 31.41^{\prime} \mathrm{S}$ & $72^{\circ} 04.63^{\prime} \mathrm{E}$ & $1 \mathrm{Nov}$ & 43 \\
\hline E3 & Meander & $48^{\circ} 42.07^{\prime} \mathrm{S}$ & $71^{\circ} 58.02^{\prime} \mathrm{E}$ & $4 \mathrm{Nov}$ & 37 \\
\hline $\mathrm{F}$ & $\begin{array}{l}\text { Polar Front } \\
\text { Zone }\end{array}$ & $48^{\circ} 37.27^{\prime} \mathrm{S}$ & $74^{\circ} 48.44^{\prime} \mathrm{E}$ & $7 \mathrm{Nov}$ & 40 \\
\hline E4W & Plateau & $48^{\circ} 47.93^{\prime} \mathrm{S}$ & $71^{\circ} 25.50^{\prime} \mathrm{E}$ & $12 \mathrm{Nov}$ & 55 \\
\hline E4E & Meander & $48^{\circ} 42.93^{\prime} \mathrm{S}$ & $72^{\circ} 33.76^{\prime} \mathrm{E}$ & 14 Nov & 79 \\
\hline A3-2 & Plateau & $50^{\circ} 37.46^{\prime} \mathrm{S}$ & $72^{\circ} 03.34^{\prime} \mathrm{E}$ & $16 \mathrm{Nov}$ & 165 \\
\hline E5 & Meander & $48^{\circ} 24.69^{\prime} \mathrm{S}$ & $71^{\circ} 53.99^{\prime} \mathrm{E}$ & $18 \mathrm{Nov}$ & 35 \\
\hline
\end{tabular}

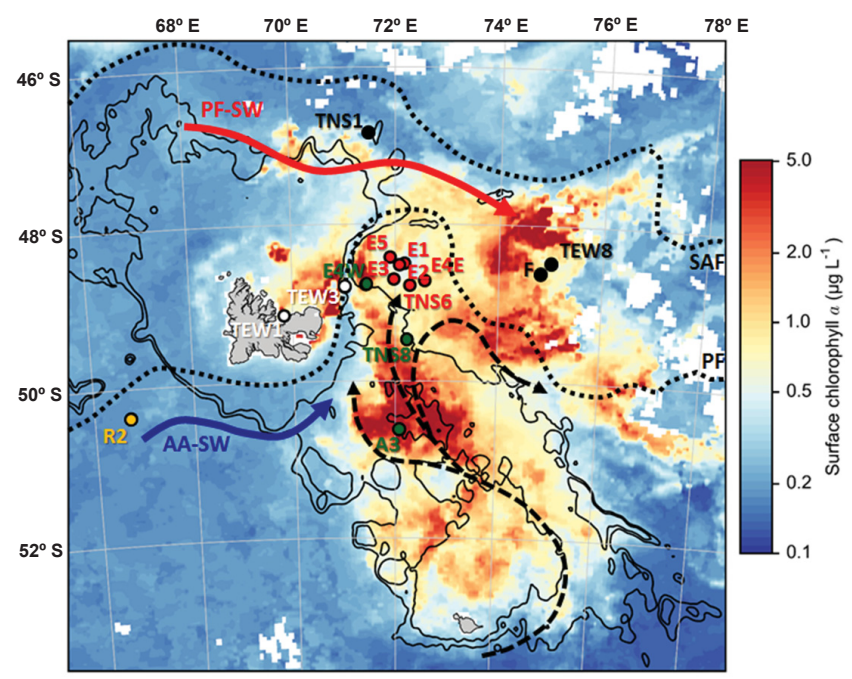

Figure 1. Map of the KEOPS-2 cruise area (Indian sector of the Southern Ocean) showing the locations of the stations. Coloured dots represent the different regions discussed in this study: yellow for HNLC, green for plateau, red for meander, black for polar front, and white for coastal stations. The general surface circulation (from Park et al., 2014) is shown with arrows; the blue arrow is the Antarctic Surface Waters, and the red arrow is the Polar Front Surface Water. The Polar Front and the Sub-Antarctic Front are represented by black dotted lines. The colour represents the detailed map of the satellite-derived surface chlorophyll $a$ concentration (MODIS level 3 product) averaged over the cruise period, and black lines are 500 and $1000 \mathrm{~m}$ isobaths.

trend lying between the two curves and depending on the $\mathrm{Si}$ uptake : Si-supply ratio occurring in the system (Fry, 2006). This could be particularly the case in the Southern Ocean, where large nutrient consumption was observed in regions characterized by intense mixing events that strongly deepen the ML and bring DSi in surface waters (e.g. Brzezinski et al., 2001; Nelson et al., 2001).
In this paper, we investigate the spatial and seasonal variability of silicon isotopic composition of both seawater $\left(\delta^{30} \mathrm{Si}_{\mathrm{DSi}}\right)$ and siliceous particles $\left(\delta^{30} \mathrm{Si}_{\mathrm{BSi}}\right)$ in deep and surface waters of the Kerguelen area during the spring period. Our specific objectives are the following.

- Describe the early-spring spatial distribution of silicon isotopes across the range of productivity observed near the Kerguelen Islands.

- Discuss the potential role of iron in regulating the Si biogeochemical cycle and isotope dynamics in the Southern Ocean surface and subsurface waters.

- Refine the net BSi production estimated by Fripiat et al. (2011a) using the appropriate spring biogeochemical conditions (DSi concentration and $\delta^{30} \mathrm{Si}$ ).

- Finally, identify and track the Si sources that fuel the phytoplankton bloom above the plateau and characterize the temporal evolution of the silicon biogeochemical cycle by combining our KEOPS-2 results with KEOPS1 data.

\section{Material and methods}

\subsection{Sample collection}

The cruise consisted of two transects north to south (TNS stations) and east to west (TEW stations) aimed at documenting the spatial extension of the bloom and its coastal-offshore gradient, and 11 long-term stations devoted to process studies (see Fig. 1 and Table 1):

- A HNLC reference station (R2) located upstream of the eastward ACC flow, south of the Kerguelen Islands, hereafter referred to as HNLC station.

- Two visits at the KEOPS-1 plateau bloom reference station (A3-1 and A3-2), and at a moderately productive station (E4W) located in the plume of chlorophyll north of $\mathrm{A} 3$, hereafter referred to as plateau stations.

- An open ocean station (F) influenced by warmer Subantarctic Surface Waters, located north of the PF, hereafter referred to as the Polar Front Zone.

- Six stations (TNS6 and E1 to E5) constituting a pseudoLagrangian survey and located in the area of PF retroflection characterized by strong mesoscale activity (Zhou et al., 2014) and hereafter referred to as meander stations.

Si isotopic compositions from a total of 224 seawater samples and 137 particulate samples are presented in this study (Table S2). The particulate samples included 91 samples collected in the ML using Niskin bottles and 46 samples coming 
from in situ pumps (ISP). At all stations, seawater and particles were collected using a CTD (conductivity-temperaturedepth) rosette equipped with $12 \mathrm{~L}$ Niskin bottles. Seawater (approximately 5 L) was immediately filtered through polycarbonate membranes (Nuclepore, $0.4 \mu \mathrm{m}$ ) using large volume filtration units. Filtered water samples were stored in the dark in acid-cleaned polypropylene bottles and membranes were dried overnight at $50^{\circ} \mathrm{C}$ and stored in polycarbonate Petri dishes at room temperature. Since particle concentration decreases with depth, deep-water particles were collected using in situ pumps at seven stations by filtering 70 to $1800 \mathrm{~L}$ of seawater through hydrophilic polyestersulfone membranes (SUPOR, $0.8 \mu \mathrm{m}$ ). Approximately $1 / 8$ of the SUPOR membranes were dedicated to silicon isotopic analysis and were dried overnight at $50{ }^{\circ} \mathrm{C}$ and stored in Petri dishes at room temperature.

Sinking particles were collected from a moored sediment trap (Technicap PPS3) that was deployed at station A3 over the central Kerguelen Plateau at 289 m (seafloor depth $527 \mathrm{~m}$ ). The sediment trap carrousel was composed of 12 sampling cups $(250 \mathrm{~mL})$ collecting sinking particles from the 21 October 2011 to 7 September 2012. Sampling intervals were programmed to be short (10-14 days) in spring and summer and longer (99 days) in autumn and winter. A description of the physical environment of the deployment together with the detailed methods for sediment trap sample processing are reported in Rembauville et al. (2015). After the BSi extraction (Rembauville et al., 2015), samples were purified and analysed for the $\mathrm{Si}$ isotopic composition as described below.

\subsection{Sample preparation}

\subsubsection{Particle digestion and BSi analyses}

The membranes (Nuclepore and SUPOR) were subjected to a wet-alkaline digestion (adapted from Ragueneau et al., 2005). BSi was dissolved in Teflon tubes using a $0.2 \mathrm{~mol} \mathrm{~L}^{-1}$ $\mathrm{NaOH}$ solution $(\mathrm{pH} 13.3)$ at $100^{\circ} \mathrm{C}$ for $40 \mathrm{~min}$ followed by neutralization with $\mathrm{HCl}\left(1 \mathrm{~mol} \mathrm{~L}^{-1}\right)$. As this digestion can also solubilize some lithogenic silica (mainly clay minerals), a second and identical digestion was applied to the membranes that were then analysed for aluminium (Al, a tracer of lithogenic source) using an inductively coupled plasma mass spectrometer (ICP-MS; detection limit = 3.18 ppb). Using the $\mathrm{Si}: \mathrm{Al}$ ratio measured in the second digestion, the lithogenic silicon dissolved in the first digestion can be estimated (Ragueneau et al., 2005). Unfortunately, the polycarbonate membranes used for silicon isotopic analysis were contaminated by Al during filtrations onboard. However, SUPOR filters as well as Al concentrations estimated on other filters (Lasbleiz et al., 2014) revealed negligible lithogenic silicon in the first leachate (on average $1.26 \%$ for SUPOR filters). Such a lithogenic contribution should not bias significantly our $\delta^{30} \mathrm{Si}$ value. Indeed, using a light end- member $\delta^{30} \mathrm{Si}_{\mathrm{LSi}}$ of $-2.3 \%$ reported in clays (Opfergelt and Delmelle, 2012) and our maximum $\delta^{30} \mathrm{Si}_{\mathrm{BSi}}(2.06 \%$ station $\mathrm{R} 2,2400 \mathrm{~m}$ ) as extreme end-members, we calculated a maximum interference in the isotopic signal of $0.05 \%$ which is similar to our analytical precision for $\delta^{30} \mathrm{Si}$. BSi concentrations were determined with a colorimetric method according to Grasshoff et al. (1999) and by ICP-MS on the same samples used to measure Si isotopic composition. Every ISP sample was analysed in full duplicates (i.e. on a second fraction of the same membrane) with a pooled standard deviation of $5.0 \pm 4.6 \%(n=58)$, which corresponds to our average reproducibility of BSi measurements, and which is slightly better than the uncertainty estimated for this method $(10 \%$, Ragueneau et al., 2005). Moreover, independent measurements of BSi concentration performed with Niskin bottles at the same stations and depths during KEOPS-2 by Lasbleiz et al. (2014) were similar to our results, suggesting that the ISP method was robust.

\subsubsection{Seawater preconcentration and DSi analyses}

A two-step preconcentration procedure adapted from the MAGIC method (Karl and Tien, 1992; Reynolds et al., 2006) was performed on seawater samples to increase $\mathrm{H}_{4} \mathrm{SiO}_{4}$ concentration and reduce the anionic matrix that could interfere with $\mathrm{Si}$ during isotopic analysis (e.g. sulfates, $\mathrm{SO}_{4}^{2-}$; Hughes et al., 2011). DSi was co-precipitated in two steps with brucite $\left(\mathrm{Mg}(\mathrm{OH})_{2}\right)$ by adding $2 \%(v / v)$, followed by $1 \%(v / v)$ of $1 \mathrm{M} \mathrm{NaOH}$ to the seawater sample. This solution was shaken and left for $1 \mathrm{~h}$ and the precipitate was recovered by centrifugation and redissolved with $1 \mathrm{M} \mathrm{HCl}$. The supernatant was removed and Si recovery was monitored by checking systematically that no detectable amount of silicic acid remained in the supernatant after co-precipitation and centrifugation. DSi concentrations in seawater samples were determined with a colorimetric method (Grasshoff et al., 1999) on the same samples as for Si isotopic composition. The average reproducibility of DSi measurements was $6.7 \%$ (calculated from 98 in-house silicon solution analyses at the $\pm 1 \mathrm{SD}$ level).

\subsection{Purification}

Separation of Si from other ions in the sample was achieved by passing the solution through a cation-exchange column (BioRad cation-exchange resin DOWEX 50W-X12, 200 to 400 mesh, in $\mathrm{H}+$ form) using the protocol described in Georg et al. (2006). After purification, systematic analysis of major elements (such as $\mathrm{Mg}, \mathrm{Ca}, \mathrm{Na}$, and $\mathrm{Al}$ ) was performed by ICP-MS to ensure sample purity prior to isotopic analyses ( $\mathrm{Si} / \mathrm{X}$ weight ratio usually $>50$ ). Si concentrations were also measured in the purified solutions to check for complete recovery. This purification step did not allow the complete removal of the anionic matrix, which consists primarily of $\mathrm{Cl}^{-}, \mathrm{SO}_{4}^{2-}$, and to a lesser extent $\mathrm{PO}_{4}^{3-}$ and $\mathrm{NO}_{3}^{-} \cdot \mathrm{Cl}^{-}$ 
originating from seawater can be neglected compared to $\mathrm{Cl}^{-}$ added as $\mathrm{HCl}$ to dissolve the brucite. Therefore the solutions dedicated to DSi isotopic measurements were analysed by anionic chromatography to control the concentration of sulfates. Indeed, in these samples, $\mathrm{SO}_{4}^{2-}$ concentrations could induce a significant shift in isotopic measurements (see the supplementary method and Van den Boorn et al., 2009, for rock digestion solutions). Thus, as proposed by Hughes et al. (2011), samples and standards used for DSi isotopic analyses were doped with sulfuric acid in large excess compared to the natural $\mathrm{SO}_{4}^{2-}$ concentrations in order to control this sulfate matrix effect.

\subsection{Isotopic measurements}

The purified and sulfate doped Si solutions were analysed for isotopic measurements on a Thermo Neptune ${ }^{+}$multicollector inductively coupled plasma mass spectrometer (MC-ICPMS; LSCE, Gif-sur-Yvette) in dry plasma mode using $\mathrm{Mg}$ external doping to correct for the mass bias (Cardinal et al., 2003; Abraham et at., 2008). Samples were injected into the plasma with an Apex desolvating nebulization system connected with a PFA nebulizer $\left(100 \mu \mathrm{L} \mathrm{m^{-1 }}{ }^{-1}\right.$ uptake rate $)$ and without additional gas. Silicon isotopic compositions $\left(\delta^{30} \mathrm{Si}\right)$ were calculated as the permil deviation from the quartz standard NBS28 (RM8546). They were measured relative to an in-house standard Quartz Merck, which was not significantly different from NBS28 (Abraham et al., 2008), analysed immediately after and before the sample, and expressed as

$\delta^{30} \mathrm{Si}(\% \circ)=\left[\frac{\left({ }^{30} \mathrm{Si} /{ }^{28} \mathrm{Si}\right) \text { sample }}{\left({ }^{30} \mathrm{Si} /{ }^{28} \mathrm{Si}\right) \text { standard }}-1\right] \times 1000$.

Blank levels were below $1 \%$ of the main signal and were subtracted from each sample and standard analysis. All measurements were carried out in a matrix composed of $\mathrm{HNO}_{3} 0.5 \mathrm{~mol} \mathrm{~L}^{-1}, \mathrm{HCl} 0.5 \mathrm{~mol} \mathrm{~L}^{-1}, \mathrm{H}_{2} \mathrm{SO}_{4} 1 \mathrm{mmol} \mathrm{L}^{-1}$, and medium-resolution mode $(M / \Delta M>6000)$ to optimize the separation of ${ }^{30} \mathrm{Si}$ peak and ${ }^{14} \mathrm{~N}^{16} \mathrm{O}$ interference and were performed on the interference-free left side of the peak (Abraham et al., 2008). $\delta^{29} \mathrm{Si}$ and $\delta^{30} \mathrm{Si}$ were compared to the mass-dependent fractionation line (Fig. S3) and samples falling outside of its analytical error were excluded from the final dataset. Typical analytical conditions are provided in Table S3.

Numerous analyses of a secondary reference material such as diatomite $\left(\delta^{30} \mathrm{Si}=1.26 \%\right.$, Reynolds et al., 2007) generated over the entire procedure indicated an average precision and a long-term analytical reproducibility (24 months) on $\delta^{30} \mathrm{Si}$ values of $1.28 \pm 0.05 \%$ ( $\left.1 \mathrm{SD}, n=128\right)$ and confirmed that no uncorrected isotopic bias occurred. All BSi samples and some DSi samples were fully replicated and measured on separate days (chemical preparation plus isotopic measurements). In these cases, the average full external reproducibility on full duplicates $\delta^{30} \mathrm{Si}$ is $0.06 \%$ ( $\left.1 \mathrm{SD}, n=108\right)$ and
$0.04 \%$ o $(n=78)$ for $\delta^{30} \mathrm{Si}_{\mathrm{BSi}}$ and $\delta^{30} \mathrm{Si}$ DSi respectively. Error bars shown in all figures correspond to the analytical reproducibility or to the full external reproducibility if greater than $0.05 \%$.

\section{Results and discussion}

\subsection{KEOPS-2 cruise, hydrological settings, and general considerations}

The KEOPS-2 expedition was conducted in the Kerguelen Plateau region (Indian sector of the Southern Ocean) from 10 October to 20 November 2011 (austral spring) on board of the R/V Marion Dufresne. The plateau acts as a barrier to the ACC, $60 \%$ of which passes north of the Kerguelen Islands, mostly associated with the SAF, while $40 \%$ is transported across the southern part of the plateau and forms the jet of the PF (Park et al., 2014). This PF current is then deflected to the north following the eastern escarpment of the plateau and forms a permanent cyclonic meandering associated with strong mesoscale activity (Park et al., 2014; Zhou et al., 2014). The circulation above the central Kerguelen Plateau is relatively weak ( $<3 \mathrm{~cm} \mathrm{~s}^{-1}$, Park et al., 2008b), providing good conditions for elevated primary production (Mongin et al., 2008). These particular hydrographic features generate contrasted biogeochemical and physical environments where phytoplankton communities will respond differently to iron availability. During KEOPS-2, the vertical distribution of water masses was characteristic of the Antarctic zone (AZ) in the vicinity of the PF (Park et al., 2014). Except for the first visit at over the plateau (A3) where they reached the surface, the remnant Winter Water (WW, generally from 100 to $400 \mathrm{~m}$ ) was capped by a homogeneous, warm, and fresh mixed layer (ML) or Antarctic Surface Water (AASW) induced by seasonal stratification. Below these subsurface waters, a subsurface temperature maximum between 400 and $1400 \mathrm{~m}$ associated with the Upper Circumpolar Deep Waters (UCDW) followed the Lower Circumpolar Deep Water (LCDW) in all of the out-plateau stations. The deeper Antarctic Bottom Waters (AABW) were found only at station $\mathrm{F}$, north of the PF.

During KEOPS-2, $\delta^{30} \mathrm{Si}_{\mathrm{DSi}}$ displayed a clear inverse relationship with silicic acid concentration, as commonly observed in the Southern Ocean (Fig. S4 in the Supplement and e.g. in Fripiat et al., 2012; De Souza et al., 2012). The water column profiles showed a general increase in DSi concentrations (Fig. 2a, c). $\delta^{30} \mathrm{Si}_{\mathrm{DSi}}$ became gradually lighter with depth (Fig. 2b, d). In the upper $500 \mathrm{~m}, \delta^{30} \mathrm{Si}_{\mathrm{BSi}}$ values were systematically lighter than $\delta^{30} \mathrm{Si}_{\mathrm{DSi}}$ values (Fig. $2 \mathrm{f}, \mathrm{h}$ ), in agreement with the preferential uptake of ${ }^{28} \mathrm{Si}$ by diatoms (De La Rocha et al., 1997). Below $500 \mathrm{~m}$ there was a slight increase in $\delta^{30} \mathrm{Si}_{\mathrm{BSi}}$ and a decrease in $\delta^{30} \mathrm{Si}_{\mathrm{DSi}}$ values, coincident with increasing DSi concentrations. In contrast to the ML, the $\delta^{30} \mathrm{Si}_{\mathrm{BSi}}$ below $500 \mathrm{~m}$ was systematically higher 
than $\delta^{30} \mathrm{Si}$ DSi (on average $1.74 \pm 0.13$ and $1.20 \pm 0.17 \%$ respectively). This observation differs significantly from the one observed in the Atlantic sector in summer by Fripiat et al. (2012), where the isotopic signature of BSi exported to depth was directly comparable to the $\delta^{30} \mathrm{Si}_{\mathrm{BSi}}$ values of particles in the ML. The surface KEOPS- $2 \delta^{30} \mathrm{Si}_{\mathrm{BSi}}$ (ranging from 0.47 to $2.04 \%$ ) and $\delta^{30} \mathrm{Si}_{\mathrm{DSi}}$ (ranging from 1.96 to $2.79 \%$ ) encompassed nearly the full range of delta results reported from previous Southern Ocean studies $(-0.7$ to $2.8 \%$ o for BSi and 0.5 to $4.4 \%$ o for DSi, e.g. De Souza et al., 2012; Fripiat et al., 2012). Recently, there have been some concerns regarding $\mathrm{Si}$ isotopic offsets among laboratories on North Atlantic data (see Brzezinski and Jones, 2015) as well as on the GEOTRACES intercalibration (Grasse et al., 2016). We have compared the deep KEOPS-2 samples, measured using a Neptune ${ }^{+}$MC-ICP-MS (this study) after a chemical purification adapted from Hughes et al. (2011) with data from KEOPS-1, measured using a Nu Instrument MCICP-MS (Fripiat et al., 2011a) after a chemical purification adapted from De La Rocha et al. (1996). Despite the two different sample processing methods and instrumentation, the two datasets show an offset of only $0.08 \%$ (Fig. S4), which is not analytically significant and allows the direct comparison between KEOPS-1 and KEOPS-2 delta values.

In general, $\delta^{30} \mathrm{Si}_{\mathrm{DSi}}$ signatures in deep waters were homogeneous and did not show large changes with depth or between stations (on average $1.28 \pm 0.08$ and $1.05 \pm 0.06 \%$ o for UCDW and LCDW respectively). There was much higher variability in $\delta^{30} \mathrm{Si}_{\mathrm{DSi}}$ in the $\mathrm{ML}$ and $\mathrm{WW}$ between stations (1.99 to 2.53 and 1.46 to $2.03 \%$ respectively; Table S4). Note that the WW exhibited systematically the largest dispersion of delta values and was systematically associated with a strong isotopic gradient toward light $\delta^{30} \mathrm{Si}_{\mathrm{DSi}}$ with depth (not shown). Consequently, the mean and median values were probably not representative of the specific Si concentration and isotopic composition of the WW. Usually, the temperature-minimum layer $\left(T_{\min }\right.$ between 1.5 and $2{ }^{\circ} \mathrm{C}$ in the Kerguelen area; Park et al., 2014) is the traditional definition of the remnant surface winter water. However, in some stations, it was not possible to clearly determine $T_{\min }$ (e.g. $\mathrm{R} 2$ and E2) and/or there was a significant salinity gradient above the $T_{\min }$ depth (e.g. F). Trull et al. (2015) have proposed that a shallower depth based on a threshold increase in salinity of 0.05 ( $S$ threshold depth) could better represent the WW characteristics. They ascribed undeterminable $T_{\min }$ to weaker winter mixing compared to the previous year and, thus, the nutrient depletion between the $T_{\min }$ and $S$ threshold depths could not be associated with recent consumption. In the following we will use the $S$ threshold approach since it is the most appropriate reference to reflect the pre-bloom biogeochemical conditions.

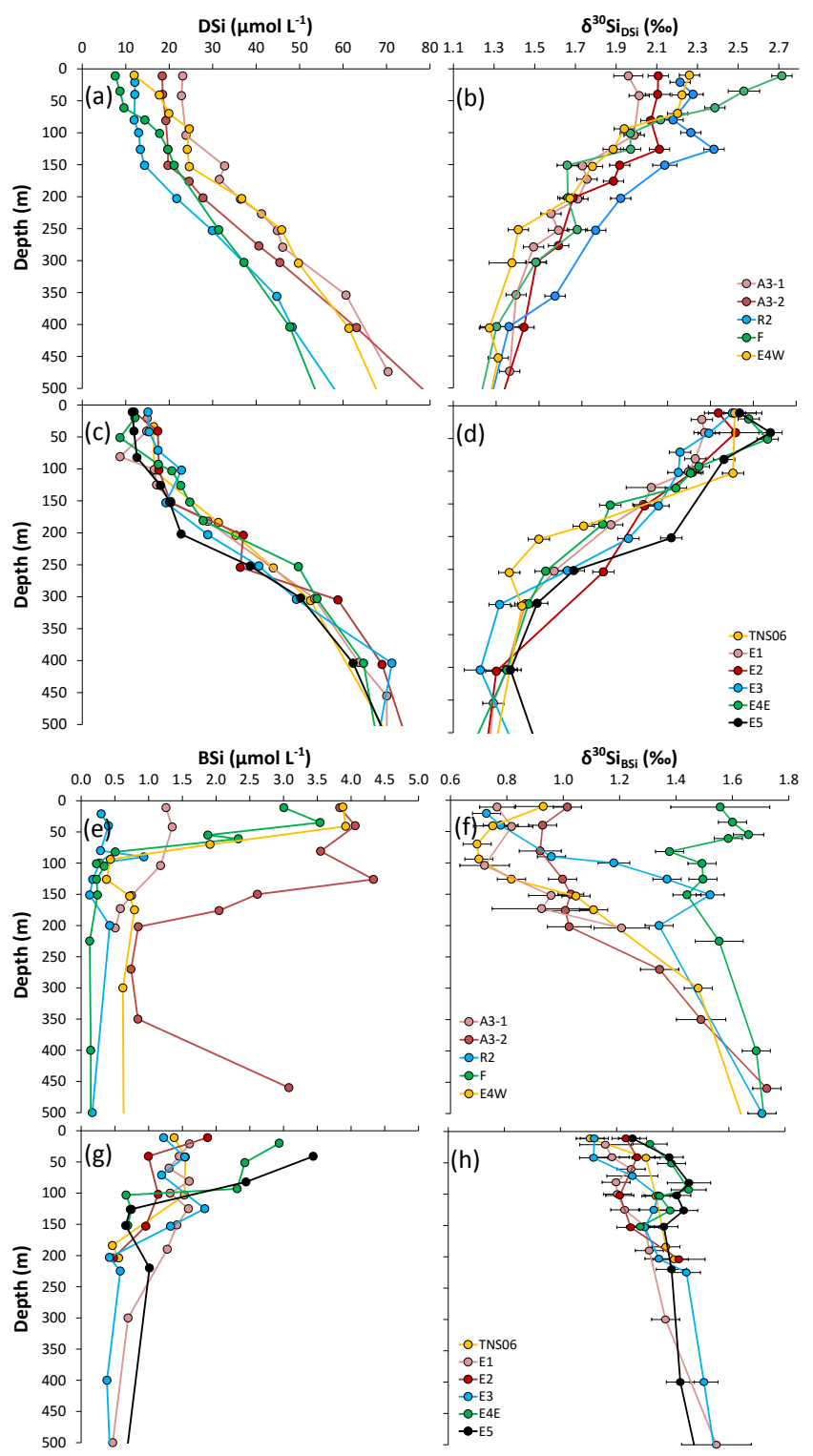

Figure 2. Vertical profiles of biogenic silica and silicic acid concentration $\left(\mu \mathrm{mol} \mathrm{L} \mathrm{L}^{-1}\right)$ and isotopic composition $(\% \mathrm{o})$ of dissolved (panels a to d) and particulate silicon (panel $\mathbf{e}$ to $\mathbf{h}$ ) for the main contrasted KEOPS-2 stations (A3, R2, E4W and F-L) and for the meander stations (TNS6, E1, E2, E3, E4E and E5).

\subsection{Distribution of Si isotopes vs. source and supply of iron}

\subsubsection{The HNLC reference station}

In the ML, the plateau and HNLC areas exhibited significantly different silicon isotopic composition of both seawater and particles, reflecting the different degrees of Si utilization by diatoms. The HNLC reference station (R2) displayed low chlorophyll $a$ and BSi and very low Si uptake rates, consistent with its iron-depleted condition and the dominance of 
non-siliceous organisms (see details in Lasbleiz et al., 2014, and Closset et al., 2014). In surface waters of the HNLC area, the concentration of biogenic silica was the lowest measured in the surface during KEOPS-2 $\left(0.30 \pm 0.03 \mu \mathrm{mol} \mathrm{L}{ }^{-1}\right)$ and its silicon isotopic composition was low $(0.73 \pm 0.04 \%$ o and similar to A3-1 (Fig. 2e, f). This is typical of nonbloom conditions and in the same range as those measured in HNLC waters of the Southern Ocean (e.g. Fripiat et al., 2011a, b; Mosseri et al., 2008). However, the HNLC station displayed unexpectedly low silicic acid concentration and heavy $\delta^{30} \mathrm{Si}_{\mathrm{DSi}}$ in the ML $\left(12.94 \pm 0.49 \mu \mathrm{mol} \mathrm{L}^{-1}\right.$ and $2.21 \pm 0.06 \%$ respectively; Fig. $2 a, b)$. This latter one is significantly heavier than the $\mathrm{Si}$ isotopic composition of the fertilized area measured a few days before $(1.99 \pm 0.03 \%$ o, A31). As already proposed by Closset et al. (2014) and Lasbleiz et al. (2014), this suggests that a development of diatoms could have occurred before our sampling, consuming a fraction of the DSi standing stock and increasing the $\delta^{30} \mathrm{Si}_{\mathrm{DSi}}$ of surface waters. The same evidence of surface production has also been deduced by Dehairs et al. (2015), who observed a slight nitrate depletion and enrichment of $\delta^{15} \mathrm{~N}-\mathrm{NO}_{3}^{-}$. The low iron concentration that prevails at this station in early spring might have been sufficient to trigger a short phytoplankton growth (dominated by nanophytoplankton; Lasbleiz et al., 2014) as soon as light conditions became favourable. Then, both the high silica dissolution to production ratio $(D: P>1)$ observed in the ML (Closset et al., 2014) and the high barium excess measured between 200 and $400 \mathrm{~m}$ (Jacquet et al., 2015) suggest that this material was exported and remineralized by the time we visited the station. This could be confirmed by the clear $\delta^{30} \mathrm{Si}_{\mathrm{BSi}}$ maximum observed between 100 and $200 \mathrm{~m}$ (Fig. 2f) that could result from the dissolution isotopically light diatoms initially produced from lighter DSi.

By contrast, all other KEOPS-2 stations outside of the HNLC were characterized by the development of large spring blooms that were not homogeneous in time and space depending on the degree, the mode, and the timing of their iron fertilization (Bowie et al., 2015; Trull et al., 2015). These blooms were organized in three main clusters related to their different iron supplies and are discussed separately in the following.

\subsubsection{The Kerguelen Plateau zone}

This area was characterized by large and recurrent blooms located southeast of the islands, mainly above the Kerguelen Plateau and delimited northward by the Polar Front (Blain et al., 2001, 2007). During our first visit to A3 (A3-1), low $\delta^{30} \mathrm{Si}_{\mathrm{DSi}}$ and $\delta^{30} \mathrm{Si}_{\mathrm{BSi}}(1.99 \pm 0.03$ and $0.77 \pm 0.05 \%$ respectively; Fig. 2b, f) were measured in the ML, indicating that biogeochemical conditions prevailing there were characteristics of a pre-bloom or early-bloom period. Indeed, low chlorophyll $a$ and BSi concentrations were observed despite high nutrients standing stocks $\left(\mathrm{H}_{4} \mathrm{SiO}_{4}\right.$ and $\mathrm{NO}_{3}^{-}$; see Blain et al., 2015 for $\mathrm{NO}_{3}^{-}$) and relatively high iron concentrations (Bowie et al., 2015).

The largest phytoplankton development was observed during the second visit to $\mathrm{A} 3$, where chlorophyll $a$ and $\mathrm{BSi}$ concentrations increased more than 2-fold over 1 month. This growth was reflected by the significant increase in both $\delta^{30} \mathrm{Si}_{\mathrm{DSi}}$ and $\delta^{30} \mathrm{Si}_{\mathrm{BSi}}$ (from $1.99 \pm 0.03$ to $2.10 \pm 0.05$ and from $0.77 \pm 0.05$ to $0.96 \pm 0.08 \%$ o respectively; Fig. $2 b$, f). There, the supply of nutrients and iron to the ML coming from the WW both in winter and during the productive period allowed a spring biogenic silica production comparable to the most productive regions in the world, such as upwelling systems or river plumes (up to $43.4 \pm 0.4 \mathrm{mmol} \mathrm{m}^{-2} \mathrm{~d}^{-1}$ for net opal production integrated over the euphotic zone, Fripiat et al., 2011a; Closset et al., 2014).

\subsubsection{The recirculation zone in the Polar Front meander}

The central part of the meander was characterized by a complex and slowly flowing water circulation associated with low to moderate dissolved iron concentrations (Bowie et al., 2015; Quéroué et al., 2015). Here, surface waters displayed generally higher $\delta^{30} \mathrm{Si}_{\mathrm{DSi}}$ signatures and lower DSi concentrations compared to above the plateau (TNS6, E1 to E5; Fig. 2d), supporting the idea of a northward surface circulation with progressive consumption and enrichment in the ${ }^{30} \mathrm{Si}$ of the dissolved pool. According to Park et al. (2014), this zone could correspond to the latest arrival of water originating from the shallow plateau located south of these stations. This would explain the delay observed between the initiation of production here and the southernmost bloom located above the plateau and in the PF plume (Fig. 1). Moreover, the radium isotope signature (Sanial et al., 2015) suggested that the southward transport of chemical elements (such as iron) across the PF could also occur and significantly fuel the phytoplankton bloom in this area, mixing the Si-poor PF ASW with heavy $\delta^{30} \mathrm{Si}_{\mathrm{DSi}}$ and Si-rich AASW with light $\delta^{30} \mathrm{Si}_{\mathrm{DSi}}$.

The moderate iron fertilization occurring in the meander should have increased both the BSi production rate and biomass, with a larger increase at the two last visits (E4E and E5, Closset et al., 2014; Lasbleiz et al., 2014). However, no clear trend was identified in the ML values of $\delta^{30} \mathrm{Si}$ DSi and $\delta^{30} \mathrm{Si}_{\mathrm{BSi}}$ since these two parameters were not significantly different from TNS6 to E4E (Table S4). This observation is strengthened by the homogeneous $\delta^{30} \mathrm{Si}$ DSi profiles in all the meander's stations (Fig. 2d). TSN6 and E1 to E3 stations display relatively homogeneous BSi concentrations and isotopic compositions. Interestingly, stations E4E and E5 were characterized by a surface accumulation of significantly lighter BSi when compared to the subsurface (respectively 1.26 and $1.46 \%$ at $\mathrm{E} 5$ ). This lower BSi isotope composition may likely result from the supply of light DSi into the ML by episodic mixing events. This would cause the DSi stock in the ML to have a lower isotopic signature than previously (as 

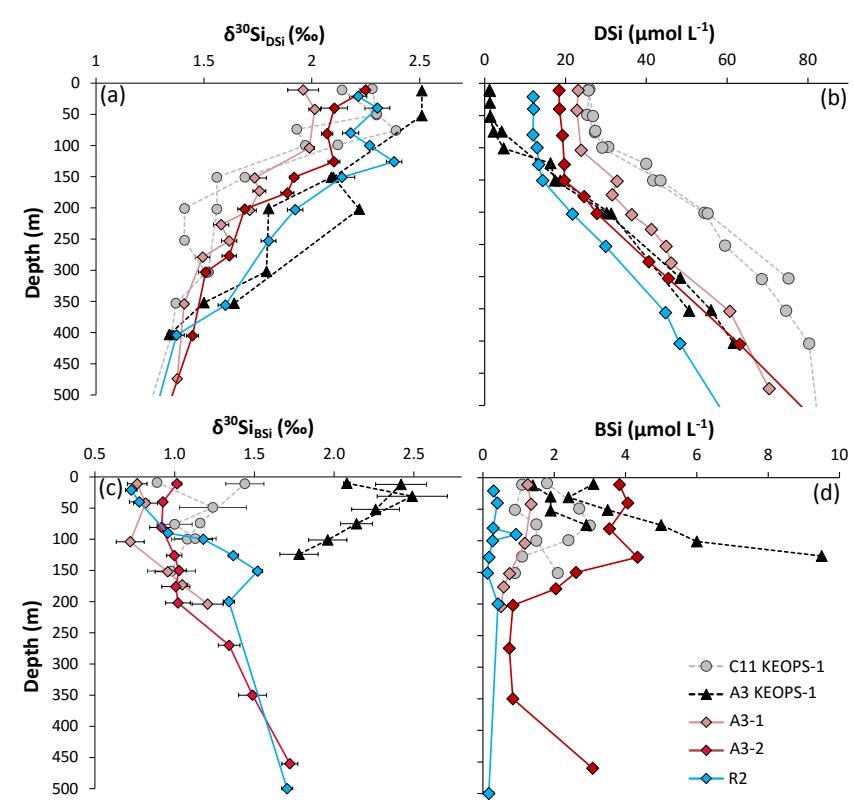

Figure 3. Seasonal evolution of the dissolved and particulate silicon isotope composition (a and $\mathbf{c}$ ) and concentration (b and $\mathbf{d}$ ) in the upper $500 \mathrm{~m}$ of the iron-fertilized (A3) and HNLC (C11 or R2) reference stations. Summer isotopic signatures (KEOPS-1, Fripiat et al., 2011a) are in grey and black colours; results from the spring period (this study) are in red and blue colour.

we observed slightly in Fig. 2d), and diatoms would produce lighter BSi at the top of the ML.

\subsubsection{The Polar Front Zone}

A plume of chlorophyll $a$ was present in the Polar Front Zone (station F, Fig. 1), extending eastward of the Kerguelen Plateau and showing strong mesoscale activity associated with the temporal and spatial variability of the Polar Front (Park et al., 2014). There, the productive waters were characterized by a shallow and relatively warm $\mathrm{ML}\left(>4^{\circ} \mathrm{C}\right)$ associated with moderate to high iron concentration (Quéroué et al., 2015; Bowie et al., 2015), providing favourable conditions for phytoplankton development. These waters were characterized by distinctly different phytoplankton communities (mostly small diatoms and nanoflagellates) than those found above the plateau (Lasbleiz et al., 2014). The Si isotopic composition of ML seawater and particles measured at $\mathrm{F}$ were the heaviest of the KEOPS-2 stations coinciding with strong Si depletion in surface water (Fig. 2b, f). These $\delta^{30} \mathrm{Si}_{\mathrm{DSi}}$ signatures fall in the range of previous reported values in the PFZ ML, from $2.05 \pm 0.03 \%$ in spring (Cardinal et al., 2005) to $2.77 \pm 0.23 \%$ in late summer (Fripiat et al., 2011a) in the Australian and Atlantic sectors of the Southern Ocean respectively. In the PFZ, heavier $\delta^{30} \mathrm{Si}$ signatures can be attributed to a higher utilization of silicic acid by diatoms leading to high net BSi production (Closset et al.,
2014). Note that higher $\delta^{30} \mathrm{Si}_{\mathrm{DSi}}$ values were also measured in the PFZ WW (on average $2.14 \pm 0.08 \%$ for all stations located north of the PF, Fig. $2 b$ ). This confirms that the source of Si is different in the PFZ than in the AZ. These PFZ waters can be advected by mixing with waters north of the Polar Front, including coastal waters, bearing higher ${ }^{30} \mathrm{Si}_{\mathrm{DSi}}$ due to the progressive export of low $\delta^{30} \mathrm{Si}_{\mathrm{BSi}}$ along their eastward advection (Bowie et al., 2015; Park et al., 2014).

\subsection{Spatio-temporal variability of $\mathrm{Si}$ mass and isotopic balance in the iron fertilized area}

By comparing the present dataset with the one collected during KEOPS-1 (summer 2005), the seasonality of the Si isotopic composition can be described, helping to refine the $\mathrm{Si}$ biogeochemical cycle in this area (Fripiat et al., 2011a; De Brauwere et al., 2012). For this purpose, the short-term temporal evolution of the bloom initiation (two visits at A3) was examined by several visits in the meander that constituted a pseudo-Lagrangian time series (covering 27 days, Table 1). The silicon isotopic properties measured in the ML during the austral spring (KEOPS-2) were significantly lighter than those measured by Fripiat et al. (2011a) at the end of summer (Fig. 3) as expected from the seasonal progression of the preferential light $\mathrm{Si}$ isotope consumption (De la Rocha et al., 1997). Temporally, the bloom above the plateau usually peaks in late November and declines gradually until January as nutrients (mainly iron and silicic acid) became limiting (Blain et al., 2007; Mongin et al., 2008). Then, a second and smaller bloom could persist at steady state until May, when the light level started to be insufficient to maintain photosynthetic activity (Blain et al., 2013). The first visit to A3 revealed relatively high DSi concentrations and low BSi and chlorophyll $a$ stocks in the ML and WW that can be associated with the initial conditions prevailing before the summer stratification (Park et al., 2014; Blain et al., 2015), whereas concentrations and $\delta^{30} \mathrm{Si}$ measured at $\mathrm{A} 3$ during KEOPS- 1 represent the conditions at the end of the season (Fig. 3). These initial conditions $\left(31.6 \pm 2.2 \mu \mathrm{mol} \mathrm{L}^{-1}\right.$ and $1.76 \pm 0.03 \%$ o for A3-1 WW DSi concentration and isotopic composition respectively) differ from the HNLC WW chosen by Fripiat et al. (2011a) as the ultimate Si source fuelling the bloom above the plateau $\left(52.5 \pm 3.3 \mu \mathrm{mol} \mathrm{L}^{-1}\right.$ and $1.5 \pm 0.0 \%$ or DSi concentration and $\delta^{30} \mathrm{Si}_{\mathrm{DSi}}$ respectively), but were not significantly different from the A3 WW reported by Fripiat et al. (2011a). Indeed, ML $\delta^{30} \mathrm{Si}_{\mathrm{DSi}}$ in the early spring was clearly off the steady-state fractionation trend (not shown) when using the same initial Si pool conditions as in Fripiat et al. (2011a). Thus, it appears that the WW Si pool isotopic and content properties of the HNLC KEOPS-1 or KEOPS-2 reference stations could not be applied as a common Si source for ML over the plateau. In the meander, the initial conditions were represented by the $\mathrm{Si}$ properties of TNS6 WW $\left(31.3 \mu \mathrm{mol} \mathrm{L}^{-1}\right.$ and $1.71 \pm 0.02 \%$ o for DSi concentration and $\delta^{30} \mathrm{Si}_{\mathrm{DSi}}$ respectively) which were 


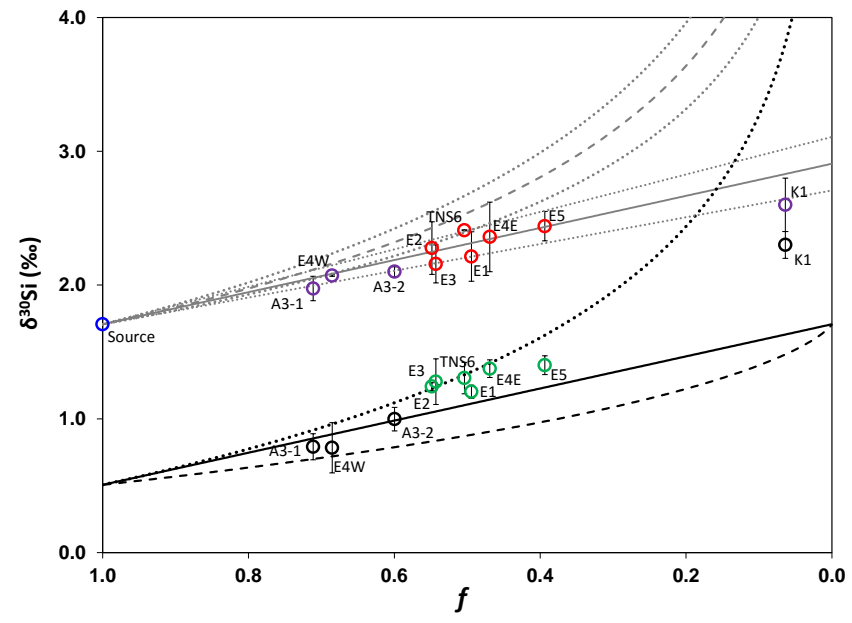

Figure 4. Silicon isotopic composition vs. remaining silicic acid $(f)$ for the different ML Si reservoirs in the iron-fertilized areas of the Kerguelen Plateau. A unique source (averaged plateau WW, blue dot, $32.9 \pm 2.2 \mu \mathrm{mol} \mathrm{Si} \mathrm{L}{ }^{-1}$ and $1.71 \pm 0.03 \%$ o) was used for all plateau and meander stations. ML dissolved Si pools above the plateau (purple dots) and in the meander (red dots) fit well with a steady-state fractionation law (grey straight line) but not with a Rayleigh distillation law (grey broken line). The grey dotted line represents the $0.2 \%$ SD of the fractionation factor. Note that given the small uncertainty of the source DSi and $\delta^{30} \mathrm{Si}$ characteristics, we have neglected this uncertainty, which is minor compared to the SD on ${ }^{30} \varepsilon$. ML particulate Si pools above the plateau (black dots) and in the meander (green dots) lie between the instantaneous and accumulated products predicted by a Rayleigh distillation model (dotted and broken lines respectively). The straight black line represents the products in the steady-state model. Summer isotopic signatures (K1 for A3 KEOPS-1) are from Fripiat et al. (2011a).

similar to those used for the plateau. This strengthens the idea of a unique Si source originating from the south and that flows northward above the shallow Kerguelen Plateau to finally reach the PF retroflection area. Thus, using the mean $\mathrm{ACC}^{30} \varepsilon$ value of $-1.2 \pm 0.2 \%$ o compiled by Fripiat et al. (2011a) and the averaged plateau WW as initial conditions, we will attempt to describe the seasonal dynamic of the Si biogeochemical cycle in the fertilized area off the Kerguelen Islands.

\subsubsection{Mixed-layer dissolved Si pool}

The seasonal evolution of $\delta^{30} \mathrm{Si}_{\mathrm{DSi}}$ in the fertilized area is best described by steady-state fractionation equations (Fig. 4). The steady-state model assumes a continuous supply of substrate and thus no change in concentration with time. It should only represent a final snapshot and cannot reflect any temporal evolution. However, when steady-state equations are used in a sequential time step, they allow consumption of substrate (Fry, 2006). In the case of the Kerguelen Plateau, Fripiat et al. (2011a) have already shown that the steady-state model better describes the seasonality of the sil- icon isotopes in the ML, and it seems that our data confirm this observation. Indeed, in Fig. 4, most of the plateau and meander ML $\delta^{30} \mathrm{Si}_{\mathrm{DSi}}$ stations were clearly off the Rayleigh fractionation trend. In contrast, all ML $\delta^{30} \mathrm{Si}_{\mathrm{DSi}}$ data align along a steady-state trend with decreasing $\mathrm{f}$ (i.e. increasing Si utilization): A3-1, A3-2, E1 to E4E meander stations, E5 and finally A3 KEOPS-1 representing the end of the growth season. These open system equations are thus appropriate to describe the Si utilization that occurred above the Kerguelen Plateau where deep and regular mixing events are expected to supply nutrients in surface waters (Park et al., 2008b). Surprisingly, in this model, meander stations exhibit higher isotopic signatures and higher DSi depletion compared to the productive plateau stations A3-2 and E4W, while they were sampled several days before these two stations. This situation was not due to a higher Si uptake in the meander ML as the net $\mathrm{BSi}$ production at A3-2 was twice that measured at E5 (Closset et al., 2014), but could be explained by a strong mixing event that occurred just before our second visit to A3. This vertical mixing was induced by strong temporary winds that supplied water with high silicic acid content and light $\delta^{30} \mathrm{Si}$ to the euphotic zone. This would thus decrease the apparent Si utilization $(f)$ and lighten the isotopic signature of seawater. Note that, as previously mentioned, no clear temporal evolution can be shown in the meander ML $\delta^{30} \mathrm{Si}_{\mathrm{DSi}}$ signatures. The hydrological conditions that lead to ML instabilities and regular mixing of the water masses were likely the reason for this situation, as we will discuss in the following.

Using KEOPS-1 HNLC WW characteristics $\left(52.5 \pm 3.3 \mu \mathrm{mol} \mathrm{Si} \mathrm{L}{ }^{-1}\right.$ and $1.5 \pm 0.0 \%$ o $)$ to represent the initial conditions of WW in the fertilized area and assuming that the system behaves following an open mode, Fripiat et al. (2011a) estimated a seasonal depletion in the ML at $5.0 \pm 0.3 \mathrm{~mol} \mathrm{Si} \mathrm{m}^{-2} \mathrm{yr}^{-1}$. By identifying a more appropriate Si source for the plateau ML-averaged plateau WW $\left(32.9 \pm 2.2 \mu \mathrm{mol} \mathrm{Si} \mathrm{L}^{-1}\right.$ and $\left.1.71 \pm 0.03 \%\right)$ and using the same equations, we can refine this calculation and reduce the seasonal net BSi production in the upper $100 \mathrm{~m}$ to $3.0 \pm 0.3 \mathrm{~mol} \mathrm{Si} \mathrm{m}^{-2} \mathrm{yr}^{-1}$. This flux is $40 \%$ lower than the previous estimate, but corresponds well to the range of published net BSi production values for the AZ (2.4 to $3.3 \mathrm{~mol} \mathrm{Si} \mathrm{m}^{-2} \mathrm{yr}^{-1}$; Pondaven et al., 2000; Nelson et al., 2002; Pollard et al., 2006) and still balances the total Si supply estimated for the plateau ML $\left(4.0 \pm 0.7 \mathrm{~mol} \mathrm{Si} \mathrm{m}^{-2} \mathrm{yr}^{-1}\right.$, Fripiat et al., 2011a). The mean net BSi production occurring during the 27 days that separate the two samplings at A3 can also be estimated at $10.7 \mathrm{mmol} \mathrm{m}^{-2} \mathrm{~d}^{-1}$ using the steadystate equations and is consistent with the $14.3 \mathrm{mmol} \mathrm{m}^{-2} \mathrm{~d}^{-1}$ computed for the same period by Closset et al. (2014) in their seasonal budget of the Si cycle above the plateau. 


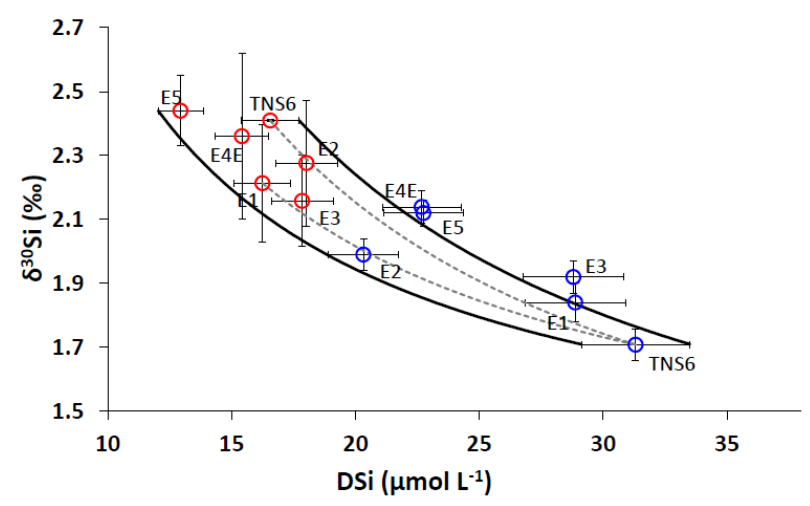

Figure 5. Potential mixing curves between TNS6-WW and the different meander ML water masses; WW is in blue and the ML is in red. The two end-members are identified by black curves. The two grey dashed lines represent the mixing curves between TNS6-WW and TNS6-ML and between TNS6-WW and E1-ML, which may explain the Si properties of E1-WW and E2-WW respectively. The ML averages and error bars were calculated based on the median values and interquartile range for each station, while the "central value" was defined using the salinity threshold method for WW.

\subsubsection{Winter waters dissolved Si pool}

By comparing WW DSi properties from KEOPS-1 HNLC and fertilized area $\left(52.5 \pm 3.3\right.$ and $\left.34.2 \pm 1.9 \mu \mathrm{mol} \mathrm{Si} \mathrm{L}^{-1}\right)$, Fripiat et al. (2011a) estimated a seasonal depletion in the 100 to $400 \mathrm{~m}$ layer of $5.5 \pm 0.3 \mathrm{~mol} \mathrm{Si} \mathrm{m}^{-2} \mathrm{yr}^{-1}$ and ascribe it to a net BSi production by a subsurface diatom population since a deep BSi and chlorophyll maximum was observed here in January (Mosseri et al., 2008; Uitz et al., 2009). The WW characteristics measured during our first visit at A3 $\left(31.5 \pm 2.2 \mu \mathrm{mol} \mathrm{Si} \mathrm{L}{ }^{-1} ; 1.76 \pm 0.03 \%\right.$ ) were similar to the one observed at the end of the productive season by Fripiat et al. (2011a), suggesting that, contrary to what was previously proposed, WW did not undergo seasonal Si uptake above the plateau. This conclusion is not contradictory to the development of a subsurface diatom community that could partly explain the deep BSi accumulation observed here during KEOPS-1. Indeed, in such communities, the BSi production may likely be sustained by a regenerated source of $\mathrm{Si}$ (high $D: P$ ratio; see Closset et al., 2014, and Fripiat et al., 2011c, at the same station and in the Australian sector of the Southern Ocean respectively) or may benefit from high diffusive fluxes ( $>1 \mathrm{mmol} \mathrm{m}^{-2} \mathrm{~d}^{-1}$, Rembauville et al., 2016) that characterize these transition layers and would not finally consume the DSi standing stock.

In contrast to the ML, the WW $\delta^{30} \mathrm{Si}_{\mathrm{DSi}}$ signatures of the fertilized area (Table S4) display significant variations (from $1.71 \pm 0.02$ at TNS6 to $2.21 \pm 0.02 \%$ at E4E). It seems unlikely that such shift of WW toward higher $\delta^{30} \mathrm{Si}$ values could be explained by the progressive consumption of silicic acid by a secondary diatom community just below the ML. Indeed, although deep silica maximum are common features in the Southern Ocean (Parslow et al., 2001), the Si uptake rates measured below the euphotic layer during KEOPS-2 were very low (Closset et al., 2014). Since this area has strong mesoscale physical activity (Zhou et al., 2014; Park et al., 2014), an alternative process that could decrease the WW DSi pool and increase the WW ${ }^{30}{ }^{S} i_{D S i}$ may be the vertical mixing between initial WW and several sequential surface ML water masses (Fig. 5). Such a process is similar to what was observed for ${ }^{30} \mathrm{Si}_{\mathrm{DSi}}$ across the major ACC meridional overturning circulation and could result here from (i) the deepening of the MLD induced by wind stress and followed by the stratification of the water column; (ii) mesoscale activity that generates negative vertical velocities of water masses. In this case, the resulting water mass should lie on a theoretical mixing curve involving the TNS6 WW and different ML water masses with Si properties located between the initial and final ML end-members (TNS6 ML and E5 ML). For example, E1 WW could be fully explained by the mixing of TNS6 WW and TNS6 ML, and E2 WW by the mixing between TNS6 WW and E1 ML. Although this hypothesis seems valuable for these two examples, the large variability of the Si isotopic properties of WW water masses prevents us from identifying, with sufficient precision, the exact end-members of these mixings. Moreover, isopycnal mixings through mesoscale eddy activity could also explain this complexity. Indeed, the intense mesoscale activity associated with the meanders of the Polar Front and with major topographic obstacles such as the Kerguelen region, allows the transport of tracers and nutrients laterally through the PF (Dufour et al., 2015). Consequently, only a range of potential mixing curves has been identified in Fig. 5, but all the meander WW falls between these two extreme situations. Thus, when the water masses joined the meander, mixing between WW and ML as well as lateral advection led to an enrichment of the Si isotopic signature and a dilution of the DSi pool of this source.

\subsubsection{Mixed-layer particulate Si pool}

While the open system model seems appropriate to describe the evolution of DSi isotopic composition, it is arguable when considering the $\delta^{30} \mathrm{Si}_{\mathrm{BSi}}$, since this model conceptually assumes the lack of BSi accumulation (Fry, 2009). As shown in Fig. 4, the signature of opal during the two KEOPS expeditions did not fall in the steady-state fractionation trend for $\mathrm{BSi}$, but rather fell between the two product curves involved in the closed model. The Rayleigh fractionation equations describe two extreme ideal situations: all the BSi produced in the ML is immediately exported from the system (the so-called instantaneous BSi, Eq. 2), or all BSi accumulates in the ML (the so-called accumulated BSi, Eq. 3). During diatom bloom development and through the seasons in the Kerguelen iron-fertilized area, the system shifted from one situation to another or remained between these two extremes depending on the $\mathrm{BSi}$ accumulation : $\mathrm{BSi}$ export ratio 
which is impacted by the bloom maturity and/or the hydrodynamical conditions of the surface waters. The instability of the ML depth at TNS6, "bloom-initiation" stations (E1, E2, and E3) and at E4E impacted the phytoplankton growth as discussed previously and may have led to important biomass export through detrainment. In these systems, diatoms did not accumulate in the ML but settled toward deeper layers, exporting carbon and BSi (Laurenceau-Cornec et al., 2015; Planchon et al., 2015). The $\mathrm{Si}$ isotopic properties at these stations felt close to the instantaneous product curve of the Rayleigh fractionation law (Fig. 4). Considering the early stage of the season during the KEOPS-2 expedition and since Si uptake rates above the plateau were among the highest reported so far for the Southern Ocean, it appears that BSi and $\mathrm{C}$ export was very low at $\mathrm{A} 3$ and $\mathrm{E} 4 \mathrm{~W}$ (Jacquet et al., 2015; Planchon et al., 2015; Rembauville et al., 2015). At $\mathrm{A} 3$ and $\mathrm{E} 4 \mathrm{~W}$ BSi accumulated in the ML, resulting in $\mathrm{Si}$ isotopic properties that seemed to be better described by the accumulated product curve of the Rayleigh model. The last two stations (E5, KEOPS-2, and A3, KEOPS-1) lay between the two curves since they combined the two biogeochemical processes (BSi accumulation and export). Indeed, the high Si uptake rates observed at E5 $\left(20.5 \pm 0.2 \mathrm{mmol} \mathrm{m}^{-2} \mathrm{~d}^{-1}\right.$; Closset et al., 2014) associated with the strengthening of the summer stratification would progressively reduce vertical $\mathrm{Si}$ supply and would support higher phytoplankton retention in the ML. KEOPS-1 expedition occurred during the decaying phase of the bloom. Thus, the biological material present in the ML at the end of summer was likely composed of old and detrital diatoms that were partly exported in December (Rembauville et al., 2015) and living cells that were produced from regenerated Si sources (Closset et al., 2014). The $\delta^{30} \mathrm{Si}_{\mathrm{BSi}}$ observed in the late-summer surface waters would be a combination of old particles that remained in the ML, with a lighter isotopic signature, and new and isotopically heavier diatoms that would increase the delta value. This situation is consistent with the strong seasonality of primary and export production that characterizes the Southern Ocean and leads to a temporal decoupling between these two processes in the ML (see e.g. Rembauville et al., 2015a).

The contrasted seasonal evolution of $\delta^{30} \mathrm{Si}_{\mathrm{DSi}}$ and $\delta^{30} \mathrm{Si}_{\mathrm{BSi}}$ (following an open or a closed system respectively) is similar to BSi and DSi isotopic offsets previously reported (e.g. Varela et al., 2004; Fripiat et al., 2012) leading to spatiotemporal variations of the $\mathrm{ML} \Delta^{30} \mathrm{Si}\left(\Delta^{30} \mathrm{Si}=\delta^{30} \mathrm{Si}_{\mathrm{BSi}}\right.$ $\left.\delta^{30} \mathrm{Si}_{\mathrm{DSi}}\right)$, with low $\Delta^{30} \mathrm{Si}$ at the end of summer when the ML silicic acid pool was highly depleted. Fripiat et al. (2012) attributed such offsets to modifications of the Si-uptake: Sisupply ratio in surface waters due to spatial variability of the biogeochemical conditions among the different zones of the ACC (AZ vs. PFZ). Our results point out an alternative: the change in $\Delta^{30} \mathrm{Si}$ can be obtained when the BSi pool in the system switches between the Rayleigh instantaneous or accumulated product depending on the BSi accumulation : $\mathrm{BSi}$ export ratio. Indeed, the processes that can affect the isotopic dynamics in this region are complex.

Thus, several explanations are possible to describe the variations of $\Delta^{30} \mathrm{Si}$ we observed (Fig. 4); however, it is difficult to discriminate which one is the most relevant.

- The fractionation factor of diatoms $\left({ }^{30} \varepsilon\right)$ may vary over the season. Since there is no study that so far has focused on ${ }^{30} \varepsilon$ seasonal variations, we have considered the fractionation factor constant. Note that this may not reflect the reality in the ocean and that the constancy of the fractionation factor can be discussed. Moreover, one in vitro study has reported inter-specific variations of the fractionation factor (Sutton et al., 2013). This could yield to seasonal variation of the mean ${ }^{30} \varepsilon$ due to the succession of diatoms species during the bloom (Lasbleiz et al., 2014).

- In the ocean, the distinction between steady-state and Rayleigh models can be tricky. Many situations, such as the Kerguelen bloom, can switch between characteristics of both closed and open system dynamics, resulting in changes in the apparent fractionation factor $\left(\Delta^{30} \mathrm{Si}\right)$. As already proposed by Fripiat et al. (2012), we suggest that these variations are mainly controlled by the Si-uptake:Si-supply ratio of the system. When the Si-uptake: Si-supply ratio is high (during the bloom period), the system roughly follows a Rayleigh fractionation model. However, when the DSi pool limits $\mathrm{Si}$ uptake (at the end of the productive period), the Siuptake : $\mathrm{Si}$-supply ratio decreases and the supply of isotopically light DSi into the ML by vertical mixing significantly decreases the $\delta^{30} \mathrm{Si}_{\mathrm{DSi}}$. The $\delta^{30} \mathrm{Si}_{\mathrm{BSi}}$ is affected differently since the BSi pool is composed of a mix of newly formed (and light) diatoms and isotopically heavy diatoms that have been produced previously in the ML. Such a process would explain why we observe late summer high $\delta^{30} \mathrm{Si}_{\mathrm{BSi}}$ associated with low $\delta^{30} \mathrm{Si}$ of the DSi pool.

- Other isotope effects, such as mixing or BSi dissolution, can affect Si pools differently and would lead to variations of the apparent fractionation factor. Mixing brings isotopically light DSi into the ML and instantaneously decreases the $\delta^{30} \mathrm{Si}$ of the DSi pool, while the dissolution of biogenic silica may affect mainly dead and light diatoms that were produced in the beginning of the bloom, resulting in a progressive increase in the $\delta^{30} \mathrm{Si}$ of the BSi pool. Such effects are temporally decoupled and would result in a decoupling of the information recorded in the dissolved and particulate phase.

To conclude, while the closed and open theoretical models seem appropriate for interpreting paleoceanographic isotope records that integrate over longer temporal scales, they have limitations when applied to the modern ocean at shorter and seasonal scales. 


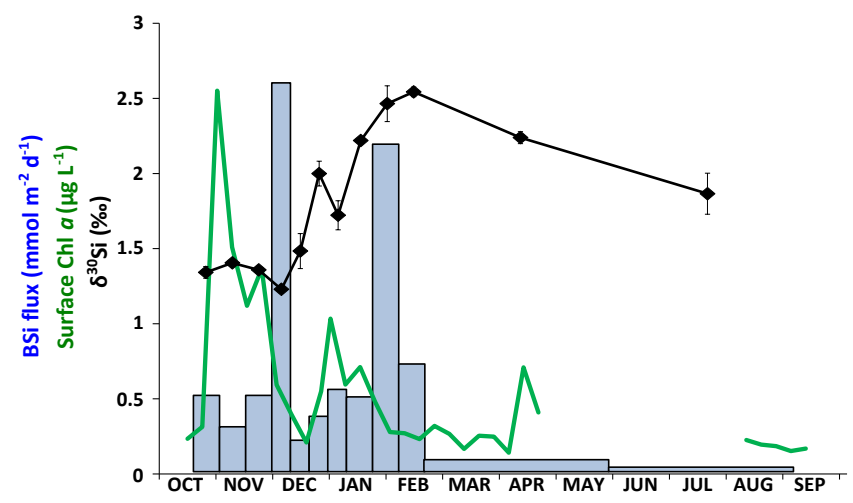

Figure 6. Surface chlorophyll $a$ concentration measured by satellite (green line), BSi fluxes collected in the sediment trap at $289 \mathrm{~m}$ (blue bars), and silicon isotopic composition of settling diatoms (black diamonds) at the $\mathrm{A} 3$ station.

\subsubsection{Deep particulate Si fluxes}

BSi export flux collected in the sediment trap located above the plateau shows two summer maxima $\left(>2 \mathrm{mmol} \mathrm{m}^{-2} \mathrm{~d}^{-1}\right.$ in early December 2011 and early January 2012) separated by a period of reduced flux (Fig. 6). In contrast, export during austral winter exhibited a long period of very low particle flux ( $<0.2 \mathrm{mmol} \mathrm{m}^{-2} \mathrm{~d}^{-1}$, from March to September 2012). These seasonal variations are associated with the evolution of surface chlorophyll $a$ concentrations with a delay of approximately 1 month, and were described in detail in Rembauville et al. (2015). This sediment trap dataset allows us to investigate the variations of exported opal $\delta^{30} \mathrm{Si}$ and subsequently the mechanisms governing the seasonal variations of Si stocks and fluxes in the ML. Recent studies have suggested that the seasonal variations of the isotopic composition of exported BSi may reflect the evolution of $\delta^{30} \mathrm{Si}_{\mathrm{BSi}}$ in the ML (Varela et al., 2004; Closset et al., 2015). In Fig. 6, we can identify five key periods in the seasonal $\mathrm{Si}$ biogeochemical cycle above the Kerguelen Plateau.

i. Early spring: the relatively low $\delta^{30} \mathrm{Si}$ (1.34 in October to $1.23 \%$ in December) did not directly relate to the isotopic signature of diatoms in the ML at the same station for the same period $(0.79 \pm 0.1 \%$ o late October, and $1.00 \pm 0.09 \%$ mid-November), but did correspond to the signature of particles collected between 200 and $450 \mathrm{~m}(1.21 \pm 0.1 \%$ late October, A3-1, and $1.34 \pm 0.07 \%$ mid-November, A3-2; Fig. 2f). Although Demarest et al. (2009) estimated a fractionation factor of $-0.55 \%$ o during the dissolution of $\mathrm{BSi}$, it seems unlikely that this process would be responsible for the heavy isotopic signature of the deep particles since dissolution rates are low during early spring (the dissolution to production ratio measured in the ML during KEOPS-2 was very low above the plateau, less than 0.1, Closset et al., 2014). Moreover, recent studies have pointed out that the isotopic signature of particles is well conserved through the water column and can be closely related to the DSi consumption in surface waters (Fripiat et al., 2012; Closset et al., 2015). Therefore, assuming that the $\delta^{30} \mathrm{Si}$ of exported BSi followed either the accumulated Rayleigh or steady-state equations, the $1.23 \%$ signature measured during the first export event corresponds to a DSi consumption ranging between 45 and $60 \%$ of the winter DSi standing stock in the ML respectively and results in a DSi concentration remaining in the ML ranging between 18 (Rayleigh) and $13 \mu \mathrm{mol} \mathrm{L}^{-1}$ (steady state) in November 2011 (1-month delay between when the signal was produced in the ML and recorded in the trap). The remaining DSi concentration calculated from Rayleigh accumulated product equation is consistent with the DSi concentration measured in the ML during the second visit to A3 in November $\left(19.7 \pm 0.3 \mu \mathrm{mol} \mathrm{L}^{-1}\right.$, Fig. $\left.2 \mathrm{a}\right)$ and confirms that, in early spring, the BSi production in the ML follows more closely to the closed system mode.

ii. Early summer: during December, the $\delta^{30} \mathrm{Si}$ of settling particles increased from 1.23 to $1.99 \%$ as a result of diatom activity in the ML. These high values cannot be explained by the steady-state model. Applying the Rayleigh equations, we estimate a consumption of $71 \%$ of the winter DSi standing stock. The assumptions behind this estimation are the following.

- The fractionation factor ${ }^{30} \varepsilon$ is constant.

- There is no significant BSi export during this period so the $\mathrm{BSi}$ accumulation: $\mathrm{BSi}$ export ratio is very high.

- There is no significant DSi supply during this period so the Si-supply: Si-uptake ratio is very low.

These two last assumptions are consistent with the situation encountered early summer, i.e. when the bloom has just started and when diatoms accumulates in the ML and have not consumed all the DSi stock. The remaining DSi concentration in the ML would be $9.5 \mu \mathrm{mol} \mathrm{L}^{-1}$ in November 2011 which is half of concentration measured at A3 mid-November but which is close to the $12 \mu \mathrm{mol} \mathrm{L}^{-1}$ measured mid-November at E5. Such an increase between the two BSi delta values corresponds to a net BSi production of $22.8 \mathrm{mmol} \mathrm{m}^{-2} \mathrm{~d}^{-1}$ (integrated over a $80 \mathrm{~m} \mathrm{ML}$ as in Closset et al., 2014). This production is half the production measured at A3-2 during $24 \mathrm{~h}$ incubations $\left(46.8 \mathrm{mmol} \mathrm{m}^{-2} \mathrm{~d}^{-1}\right.$ Closset et al., 2014). The difference can be explained by the different integration time associated with the two methods: the $\delta^{30} \mathrm{Si}$ of exported $\mathrm{BSi}$ integrates 1 month, while a daily incubation only represents a snapshot of BSi production. The high production rate measured from $24 \mathrm{~h}$ incubation may not have been maintained at this rate for 
the whole of December. Additionally, DSi supply also occurs in summer (Fripiat et al., 2011a; Closset et al., 2014), a process that is not included in Rayleigh equations but causes an underestimate BSi production.

iii. Mid-summer. The sharp decrease in $\delta^{30} \mathrm{Si}$ of settling particles observed in January 2012 (from 1.99 to $1.72 \%$ ) can be associated with a strong vertical mixing event that brings new and isotopically light DSi into the ML. This phenomenon has already been observed in open ocean sediment trap time series in the Antarctic Zone (Varela et al., 2004; Closset et al., 2015). Assuming that at this time of vertical mixing, the system behaves following an open mode (Fig. 4), this $0.27 \%$ o ${ }^{30} \mathrm{Si}_{\mathrm{BSi}}$ decrease would correspond to the same change in $\delta^{30} \mathrm{Si}_{\mathrm{DSi}}$ and to an increase of $7.6 \mu \mathrm{mol} \mathrm{L}^{-1}$ in the DSi concentration in the ML (1.99 and $1.72 \%$ o correspond to a DSi concentration of 32.5 and $25.0 \mu \mathrm{mol} \mathrm{L}^{-1}$ respectively). The assumptions behind this calculation are the following.

- The fractionation factor ${ }^{30} \varepsilon$ is constant.

- The DSi supplied into the system has the same isotopic signature as the source. This assumption is realistic since the mixing event brings DSi from WW (source) into the ML.

- All the BSi and the remaining DSi should be removed from the system. We cannot verify this last assumption, but we can expect that a large fraction of the BSi was exported out of the ML mid-summer. This might be supported by the deep silica maximum observed late summer below the ML $(150 \mathrm{~m})$ by Mosseri et al. (2008) at the same station.

The subsequent DSi stock in the ML would be $17.1 \mu \mathrm{mol} \mathrm{L}{ }^{-1}$ in December 2011. Using a simplistic approach (see the supplementary method) we estimate that such Si supply would require a ML deepening of ca. $37 \mathrm{~m}$, which is consistent with the order of magnitude of ML variation in this area (Park et al., 2008b). High wind events could induce vertical mixing of the upper ocean, entraining cold water into the ML and bringing DSi into the euphotic zone. Integrating the DSi increase of $7.56 \mu \mathrm{mol} \mathrm{L}^{-1}$ over this new ML $(80 \mathrm{~m}+37 \mathrm{~m}) \mathrm{sug}$ gests a supply of $884 \mathrm{mmol} \mathrm{m}^{-2}$. Such a mixing event would represent approximately $74 \%$ of the total summer supply (1200 $\mathrm{mmol} \mathrm{m}^{-2}$; Closset et al., 2014) and would allow the second bloom to appear as observed in January 2012 (Rembauville et al., 2015). Sporadic upwelling through Ekman pumping above the plateau (see Gille et al., 2014) could also bring DSi into the ML, but considering its low intensity, it is unlikely that it could sustain the needed flux of DSi. Note that if the closed model is considered, the $\delta^{30} \mathrm{Si}_{\mathrm{BSi}}$ signal would correspond to a consumption of $64 \%$ of the winter DSi stock and thus an increase in the DSi concentration of $2.3 \mu \mathrm{mol} \mathrm{L}{ }^{-1}$ in the ML. This value would imply a deepening of the ML by only $8.75 \mathrm{~m}$ and a summer supply of $204 \mathrm{mmol} \mathrm{m}^{-2}$ which does not correspond to the one estimated by Closset et al. (2014). This highlights, as proposed previously, the fact that $\mathrm{BSi}$ isotopic and mass balance can follow either a closed or an open mode depending on physical and biogeochemical conditions which vary during the growing season.

iv. Late summer: the $\delta^{30} \mathrm{Si}$ increased from 1.72 to $2.54 \%$ o due to a second episode of enhanced biological activity in the ML. Using the Rayleigh equations (Fig. 4), this highest value corresponds to a consumption of $82 \%$ of the winter DSi standing stock which results in a ML DSi concentration of $6.05 \mu \mathrm{mol} \mathrm{L}^{-1}$ and thus a consumption of $10.9 \mu \mathrm{mol} \mathrm{L}^{-1}$ of the DSi concentration in the ML between December 2011 and the end of January 2012 (52 days). Integrated over a $80 \mathrm{~m} \mathrm{ML}$, this value corresponds to a net $\mathrm{BSi}$ production of $16 \mathrm{mmol} \mathrm{m}^{-2} \mathrm{~d}^{-1}$. This production is consistent with the mean net BSi production of $10 \mathrm{mmol} \mathrm{m}^{-2} \mathrm{~d}^{-1}$ estimated for the same period by Closset et al. (2014) which decreases progressively to values lower than $1 \mathrm{mmol} \mathrm{m}^{-2} \mathrm{~d}^{-1}$.

v. Winter: from March to September, the $\delta^{30} \mathrm{Si}$ of settling particles remained relatively heavy but decreased gradually toward lower values as winter deep convection progressively took place above the plateau (Blain et al., 2013).

\section{Conclusions}

The spatial distribution of $\delta^{30} \mathrm{Si}$ of seawater and particulate matter in the ML was strongly impacted by the complex structure of water masses generated by the interaction between the PF and the bathymetry. In contrast, in deeper layers $(>500 \mathrm{~m}), \delta^{30} \mathrm{Si}_{\mathrm{DSi}}$ was remarkably homogeneous (on average $1.28 \pm 0.08$ and $1.05 \pm 0.06 \%$ o for UCDW and LCDW respectively) and deep $\delta^{30} \mathrm{Si}_{\mathrm{BSi}}$ exhibited constant values in all out-plateau KEOPS- 2 stations (on average $1.74 \pm 0.13 \%$ ) , suggesting that dissolution of opal did not have any significant isotopic effect during this early season.

The measured silicon properties of the ML can be considered as representative of the bloom initiation as also supported by companion studies from the same cruise (Blain et al., 2015; Cavagna et al., 2015; Closset et al., 2014; Lasbleiz et al., 2014). During this period, the Kerguelen area was characterized by a mosaic of biogeochemical environments (Trull et al., 2015). The HNLC area, strongly iron-limited station R2, exhibited very low biomass, low BSi production, and isotopically light $\mathrm{BSi}$. However, moderate production in agreement with other proxies (Closset et al., 2014; Dehairs et al., 2015; Jacquet et al., 2015) could explain the relatively high $\delta^{30} \mathrm{Si}_{\mathrm{DSi}}$ values measured at this station, precluding its 
application as a non-productive reference station for the silicon biogeochemical cycle. The iron flux in the ML above the plateau strongly stimulated diatom production, increasing significantly its $\delta^{30} \mathrm{Si}_{\mathrm{BSi}}$ (from $0.77 \pm 0.05$ to $0.96 \pm 0.08 \%$ o over 27 days during KEOPS-2) and simultaneously enriching the ML in ${ }^{30} \mathrm{Si}$ (up to $2.10 \pm 0.05 \%$ ). North of the PF, stocks and $\mathrm{Si}$ isotopic composition of seawater and particles were respectively lower and heavier than above the plateau, in accordance with its PFZ characteristics as already reported by Cardinal et al. (2007, 2005), Varela et al. (2004), and Fripiat et al. (2011b) in other sectors of the Southern Ocean. The situation was different in the meander since these stations received only moderate and sporadic iron supplies. There, nonoptimal light-mixing regime and nutrient availability (including iron) delayed the bloom development and led the system to behave near steady state with low DSi utilization. Indeed, both $\mathrm{Si}$ isotopic signatures and mass balance did not evolve significantly in the meander ML.

Our $\mathrm{Si}$ isotopic data allow identification of the initial conditions before diatom growth, $\mathrm{Si}$ sources, and the connections between different water masses through local circulation. The same Si source (WW plateau and not WW HNLC as initially thought) can be used for both the plateau and meander stations, suggesting that water masses and the ML bloom originated from the south-eastern part of the Kerguelen Plateau and spread northward. The $\mathrm{Si}$ properties of this source $\left(32.9 \pm 2.2 \mu \mathrm{mol} \mathrm{Si} \mathrm{L}^{-1}\right.$ and $1.71 \pm 0.03 \%$ ) allow us to refine the seasonal net BSi production at $3.0 \pm 0.3 \mathrm{~mol} \mathrm{Si} \mathrm{m}^{-2} \mathrm{yr}^{-1}$ above the plateau (instead of the $10.5 \pm 1.3 \mathrm{~mol} \mathrm{Si} \mathrm{m}^{-2} \mathrm{yr}^{-1}$ estimated by Fripiat et al., 2011a), which is more consistent with the published values for the $\mathrm{AZ}$ ( 2.4 to $3.3 \mathrm{~mol} \mathrm{Si} \mathrm{m}^{-2} \mathrm{yr}^{-1}$; e.g. Pondaven et al., 2000; Nelson et al., 2002). This suggests that, even if the iron fertilization in some regions of the Southern Ocean stimulates the uptake of $\mathrm{C}$ and $\mathrm{N}$ and the production of organic matter compared to non-fertilized area, it does not necessary enhance consumption of silicic acid and production of BSi. This observation can be explained by the decoupling between the biogeochemical cycles of $\mathrm{Si}, \mathrm{C}$, and $\mathrm{N}$ of diatom communities living under different biogeochemical conditions. These distinctive local communities may induce variations of the efficiency of the silicon pump (Dugdale et al., 1995) that preferentially recycles organic matter over biogenic silica in surface waters and thus leads to moderate net BSi production despite high primary production. Indeed, other recent studies in the Southern Ocean have highlighted the fact that diatom community composition could better explain differences in silicification than physiological response to iron enrichment (see Baines et al., 2010; Assmy et al., 2013). Moreover, the isotope characteristics of the WW were similar through the whole season, meaning there was no net BSi production above the plateau. In contrast, in the meander the variation of the WW Si characteristics (concentration and isotopic composition) can be explained by successive mixings between the ML and WW or by lateral advection.
In the naturally iron-fertilized area of Kerguelen, we have shown that the dissolved and particulate Si pools were temporally decoupled. In this highly productive area, strong activity that promoted vertical and lateral nutrient exchanges, drove the evolution of $\delta^{30} \mathrm{Si}_{\mathrm{DSi}}$ to follow the steady-state equations, while the $\delta^{30} \mathrm{Si}_{\mathrm{BSi}}$ seemed to follow more closely the Rayleigh equations. Depending on the regime of BSi export (e.g. BSi accumulation in the ML in early spring vs. the massive export event at the end of the productive season), the ML $\delta^{30} \mathrm{Si}_{\mathrm{BSi}}$ can be described by the accumulation or instantaneous product, or could lie between these two ideal situations. If confirmed in other productive regions of the Southern Ocean, this observation could have great implications for paleoceanographic studies. Indeed, the $\delta^{30} \mathrm{Si}_{\mathrm{BSi}}$ of sediments is currently used as a proxy for past reconstructions of surface Si utilization (e.g. De la Rocha et al., 1998; Ehlert et al., 2013). In these studies, the isotopic signature of sedimentary opal is used to calculate the ${ }^{30} \mathrm{Si}_{\mathrm{DSi}}$ and the extent of DSi consumption in surface waters using either the Rayleigh or steady-state equations without taking into account the possible decoupling between $\delta^{30} \mathrm{Si}_{\mathrm{DSi}}$ and $\delta^{30} \mathrm{Si}_{\mathrm{BSi}}$ and its seasonal variability.

Finally, we have identified and quantified the processes that control the biogeochemical cycle of silicon in the ML over nearly 1 complete year. We show that the $\delta^{30} \mathrm{Si}$ of settling diatoms collected in sediment traps is a powerful proxy to quantify Si fluxes in the ML, such as silicic acid consumption in spring and summer or Si supply to the ML during mixing events.

\section{Data availability}

All original data from this paper are available in the Supplement section. Si isotope data are also available from the GEOTRACES International Data Assembly Centre http: //www.bodc.ac.uk/geotraces/. Moreover, all KEOPS-2 data are available from the French CYBER data centre: http: //keops2.obs-vlfr.fr/.

\section{The Supplement related to this article is available online at doi:10.5194/bg-13-6049-2016-supplement.}

Acknowledgements. The authors would like to thank B. Quéguiner as the KEOPS-2 chief scientist, the captain, and the crew of the R/V Marion-Dufresne II for assistance on board; Mustapha Benrahmoune (LOCEAN, CNRS) and Irina Djouraev (LOCEAN, IRD) for their help in sample processing and $\mathrm{Si}$ and $\mathrm{Al}$ concentrations measurements; and Heather McNair for improvement of English. We are grateful to G. de Souza and one anonymous reviewer for their constructive comments that helped us to improve the manuscript. The research leading to these results on silicon has been funded by the European Union Seventh Framework 
Programme under grant agreement no. 294146 (MuSiCC Marie Curie CIG). KEOPS-2 was supported by the French Research program of INSU-CNRS LEFE-CYBER (Les enveloppes fluides et l'environnement - Cycles biogéochimiques, environnement et ressources), the French ANR (Agence Nationale de la Recherche, SIMI-6 program), the French CNES (Centre National d'Etudes Spatiales) and the French Polar Institute IPEV (Institut Polaire Paul-Emile Victor). Publication fees were supported by the project "FP7 post-grant Open Access Pilot".

Edited by: C. Woulds

Reviewed by: two anonymous referees

\section{References}

Abraham, K., Opfergelt, S., Fripiat, F., Cavagna, A.-J., de Jong, J. T. M., Foley, S. F., André, L., and Cardinal, D.: $\delta^{30} \mathrm{Si}$ and $\delta^{29} \mathrm{Si}$ Determination on USGS BHVO-1 and BHVO-2 Reference Materials with a New Configuration on a Nu Plasma Multi-Collector ICP-MS, Geostand. Geoanal. Res., 32, 193-202, 2008.

Assmy P., Smetacek V., Montresor M., Klaas C., Henjes J., Strass V. H., Arrieta J. M., Bathmann U., Berg G. M., Breitbarth E., Cisewski B., Friedrich L., Fuchs N., Herndl G. J., Jansen S., Krägefsky S., Latasa M., Peeken I., Röttgers R., Scharek R., Schüller S. E., Steigenberger S., Webb A., and Wolf-Gladrow D.: Thick-shelled, grazed protected diatoms decouple ocean carbon and silicon cycles in the iron-limited Antarctic Circumpolar Current, PNAS, 110, 20633, doi:10.1073/pnas.1309345110, 2013.

Baines, S., Twining B. S., Brzezinski M. A., Nelson D. M., and Fisher N. S.: Causes and biogeochemical implications of regional differences in silicification of marine diatoms, Global Biogeochem. Cy., 24, GB4031, doi:10.1029/2010GB003856, 2010

Blain, S., Tréguer, P., Belviso, S., Bucciarelli, E., Denis, M., Desabre, S., Fiala, M., Martin Jézéquel, V., Le Fèvre, J., Mayzaud, P., Marty, J.-C., and Razouls, S.: A biogeochemical study of the island mass effect in the context of the iron hypothesis: Kerguelen Islands, Southern Ocean, Deep-Sea Research Pt. I, 48, 163-187, 2001.

Blain, S., Quéguiner, B., Armand, L., Belviso, S., Bombled, B., Bopp, L., Bowie, A., Brunet, C., Brussaard, C., Carlotti, F., Christaki, U., Corbière, A., Durand, I., Ebersbach, F., Fuda, J.L., Garcia, N., Gerringa, L., Griffiths, B., Guigue, C., Guillerm, C., Jacquet, S., Jeandel, C., Laan, P., Lefèvre, D., Lo Monaco, C., Malits, A., Mosseri, J., Obernosterer, I., Park, Y.-H., Picheral, M., Pondaven, P., Remenyi, T., Sandroni, V., Sarthou, G., Savoye, N., Scouarnec, L., Souhaut, M., Thuiller, D., Timmermans, K., Trull, T., Uitz, J., van Beek, P., Veldhuis, M., Vincent, D., Viollier, E., Vong, L., and Wagener, T.: Effect of natural iron fertilization on carbon sequestration in the Southern Ocean, Nature, 446, 10701075, doi:10.1038/nature05700, 2007.

Blain, S., Renaut, S., Xing, X., Claustre, H., and Guinet, C.: Instrumented elephant seals reveal the seasonality in chlorophyll and light-mixing regime in the iron-fertilized Southern Ocean, Geophys. Res. Lett., 40, 1-5, doi:10.1002/2013GL058065, 2013.

Blain, S., Capparos, J., Guéneuguès, A., Obernosterer, I., and Oriol, L.: Distributions and stoichiometry of dissolved nitrogen and phosphorus in the iron-fertilized region near Kerguelen (South- ern Ocean), Biogeosciences, 12, 623-635, doi:10.5194/bg-12623-2015, 2015.

Bowie, A. R., van der Merwe, P., Quéroué, F., Trull, T., Fourquez, M., Planchon, F., Sarthou, G., Chever, F., Townsend, A. T., Obernosterer, I., Sallée, J.-B., and Blain, S.: Iron budgets for three distinct biogeochemical sites around the Kerguelen Archipelago (Southern Ocean) during the natural fertilisation study, KEOPS2, Biogeosciences, 12, 4421-4445, doi:10.5194/bg-12-44212015, 2015.

Boyd, P. W and Trull, T. W.: Understanding the export of biogenic particles in oceanic waters: Is there concensus?, Prog. Oceanogr., 72, 276-312, 2007.

Brzezinski, M. A., Nelson, D. M., Franck, V. M., and Sigmon, D. E.: Silicon dynamics within an intense open-ocean diatom bloom in the Pacific sector of the Southern Ocean, Deep-Sea Res. Pt. II, 48, 3997-4018, 2001.

Brzezinski, M. A. and Jones J. L.: Coupling of the distribution of silicon isotopes to the meridional overturning circulation of the North Atlantic Ocean, Deep-Sea Res. PT. II, 1, 79-88, 2015.

Buesseler, K. O.: The decoupling of production and particulate export in the surface ocean, Global Biogeochem. Cy., 12, 297-310, 1998.

Cao, Z., Frank, M., Dai, M., Grasse, P., and Ehlert, C.: Silicon isotope constraints on sources and utilization od silicic acid in the northern South China Sea, Geochim. Cosmochim. Ac., 97, 88104, 2012.

Cardinal, D., Alleman, L. Y., De Jong, J., Ziegler, K., and André, L.: Isotopic composition of silicon measured by multicollector plasma source mass spectrometry in dry plasma mode, J. Anal. Atom. Spectrom., 18, 213-218, 2003.

Cardinal, D., Alleman, L. Y., Dehairs, F., Savoye, N., Trull, T. W., and André, L.: Relevance of silicon isotopes to Si-nutrient utilization and Si-source assessment in Antarctic waters, Global Biogeochem. Cy., 19, GB2007, doi:10.1029/2004GB002364, 2005.

Cardinal, D., Savoye, N., Trull, T. W., Dehairs, F., Kopczynska, E. E., Fripiat, F., Tison, J.-L., and André, L.: Silicon isotopes in spring Southern Ocean diatoms: Large zonal changes despite homogeneity among size fractions, Mar. Chem., 106, 46-62, 2007.

Cavagna, A.-J., Fripiat, F., Dehairs, F., Wolf-Gladrow, D., Cisewski, B., Savoye, N., André, L., and Cardinal, D.: Silicon uptake and supply during a Southern Ocean iron fertilization experiment (EIFEX) tracked by Si isotopes, Limnol. Oceanogr., 56, 147160, doi:10.4319/lo.2011.56.1.0147, 2011.

Cavagna, A. J., Fripiat, F., Elskens, M., Mangion, P., Chirurgien, L., Closset, I., Lasbleiz, M., Florez-Leiva, L., Cardinal, D., Leblanc, K., Fernandez, C., Lefèvre, D., Oriol, L., Blain, S., Quéguiner, B., and Dehairs, F.: Production regime and associated N cycling in the vicinity of Kerguelen Island, Southern Ocean, Biogeosciences, 12, 6515-6528, doi:10.5194/bg-12-6515-2015, 2015.

Closset, I., Lasbleiz, M., Leblanc, K., Quéguiner, B., Cavagna, A.J., Elskens, M., Navez, J., and Cardinal, D.: Seasonal evolution of net and regenerated silica production around a natural $\mathrm{Fe}$ fertilized area in the Southern Ocean estimated with $\mathrm{Si}$ isotopic approaches, Biogeosciences, 11, 5827-5846, doi:10.5194/bg-115827-2014, 2014.

Closset, I., Cardinal, D., Bray, S., Thil, F., Djouraev, I., RigualHernandez, A. S., and Trull, T.: Seasonal variations, origin and fate of settling diatoms in the Southern Ocean tracked by silicon 
isotope records in deep sediment traps, Global Biogeochem. Cy., 29, 1495-1510, doi:10.1002/2015GB005180, 2015.

De Baar, H. J. W., Boys, P. W., Coale, K. H., Landry, M. R., Tsuda, A., Assmy, P., Bakker, D. C. E., Bozec, Y., Barber, R. T., Brzezinski, M. A., Buesseler, K. O., Boyé, M., Croot, P. L., Gervais, F., Gorbunov, M. Y., Harrison, P. J., Hiscock, W. T., Laan, P., Lancelot, C., Law, C. S., Levasseur, M., Marchetti, A., Millero, F. J., Nishioka, J., Nojiri, Y., van Oijen, T., Riebesell, U., Rijkenberg, M. J. A., Saito, H., Takeda, S., Timmermans, K. R., Veldhuis, M. J. W., Waite, A. M., and Wong, C.-S.: Synthesis of iron fertilization experiments: From the Iron Age in the Age of Enlightenment, J. Geophys. Res., 110, C09S16, doi:10.1029/2004JC002601, 2005.

De Brauwere, A., Fripiat, F., Cardinal, D., Cavagna, A.-J., De Ridder, F., André, L., and Elskens, M.: Isotopic model of oceanic silicon cycling: The Kerguelen Plateau case study, Deep-Sea Res. Pt. I, 70, 42-59, 2012.

Dehairs, F., Fripiat, F., Cavagna, A.-J., Trull, T. W., Fernandez, C., Davies, D., Roukaerts, A., Fonseca Batista, D., Planchon, F., and Elskens, M.: Nitrogen cycling in the Southern Ocean Kerguelen Plateau area: evidence for significant surface nitrification from nitrate isotopic compositions, Biogeosciences, 12, 1459-1482, doi:10.5194/bg-12-1459-2015, 2015.

De La Rocha, C. L., Brzezinski, M. A., and DeNiro, M. J.: Purification, Recovery, and Laser-Driven Fluorination of Silicon from Dissolved and Particulate Silica for the Measurement of Natural Stable Isotope Abundances, Anal. Chem., 68, 3746-3750, 1996.

De La Rocha, C. L., Brzezinski, M. A., and DeNiro, M. J.: Fractionation of silicon isotopes by marine diatoms during biogenic silica formation, Geochim. Cosmochim. Ac., 61, 5051-5056, 1997.

De La Rocha, C. L., Brzezinski, M. A., DeNiro, M. J., and Shemesh, A.: Silicon-isotope composition of diatoms as an indicator of past oceanic change, Nature, 395, 680-683, 1998.

De La Rocha, C. L., Hutchins, D. A., Brzezinski, M. A., and Zhang, Y.: Effects of iron and zinc deficiency on elemental composition and silica production by diatoms, Mar. Ecol.-Prog. Ser., 195, 7179, 2000.

De Souza, G. F., Reynolds, B. C., Rickli, J., Frank, M., Saito, M. A., Gerringa, L. J. A., and Bourdon, B.: Southern Ocean control of silicon stable isotope distribution in the deep Atlantic Ocean, Global Biogeochem. Cy., 26, GB2035, doi:10.1029/2011GB004141, 2012.

Demarest, M. S., Brzezinski, M. A., and Beucher, C. P.: Fractionation of silicon isotopes during biogenic silica dissolution, Geochim. Cosmochim. Ac., 73, 5572-5583, doi:10.1016/j.gca.2009.06.019, 2009.

Dufour, C. O., Griffies, S. M., De Souza, G. F., Frenger, I., Morrison, A. K., Palter, J. B., Sarmiento, J. L., Galbraith, E. D., Dunne, J. P., Anderson, W. G., and Salter, R. D.: Role of Mesoscale Eddies in Cross-Frontal Transport of Heat and Biogeochemical Tracers in the Southern Ocean, J. Phys. Oceanogr., 45, 30573081, doi:10.1175/JPO-D-14-0240.1, 2015.

Dugdale, R. C., Wilkerson, F. P., and Minas, H. J.: The role of a silicate pump in driving new production, Deep-Sea Res. Pt. I, 42, 697-719, 1995

Ehlert, C., Grasse, P., and Frank, M.: Changes in silicate utilization and upwelling intensity off Peru since the Last Glacial Maximum - insights from silicon and neodymium isotopes, Quaternary Sci. Rev., 72, 18-35, 2013.
Fripiat, F., Cavagna, A.-J., Savoye, N., Dehairs, F., André, L., and Cardinal, D.: Isotopic constraints on the Si-biogeochemical cycle of the Antarctic Zone in the Kerguelen area (KEOPS), Mar. Chem., 123, 11-22, doi:10.1016/j.marchem.2010.08.005, $2011 \mathrm{a}$.

Fripiat, F., Cavagna, A.-J., Dehairs, F., Speich, S., André, L., and Cardinal, D.: Silicon pool dynamics and biogenic silica export in the Southern Ocean inferred from Si-isotopes, Ocean Sci., 7, 533-547, doi:10.5194/os-7-533-2011, 2011b.

Fripiat, F., Leblanc, K., Elskens, M., Cavagna, A.-J., Armand, L., André, L., Dehairs, F., and Cardinal, D.: Efficient silicon recycling in summer in both the Polar Frontal and Subantarctic Zones of the Southern Ocean, Mar. Ecol.-Prog. Ser., 435, 47-61, doi:10.3354/meps09237, 2011c.

Fripiat, F., Cavagna, A.-J., Dehairs, F., de Brauwere, A., André, L., and Cardinal, D.: Processes controlling the Si-isotopic composition in the Southern Ocean and application for paleoceanography, Biogeosciences, 9, 2443-2457, doi:10.5194/bg-9-24432012, 2012.

Fry, B.: Stable Isotope Ecology, Springer, New York, 308 pp., 2006.

Georg, R. B., Reynolds, B. C., Frank, M., and Halliday, A. N.: New sample preparation techniques for the determination of $\mathrm{Si}$ isotopic compositions using MC-ICPMS, Chem. Geol., 235, 95104, 2006.

Gille, S. T., Carranza, M. M., Cambra, R., and Morrow, R.: Windinduced upwelling in the Kerguelen Plateau region, Biogeosciences, 11, 6389-6400, doi:10.5194/bg-11-6389-2014, 2014.

Grasse, P., Brzezinski, M. A., Cardinal, D., de Souza, G. F., Andersson, P., Closset, I., Cao, Z., Dai, M., Ehlert, C., Estrade, N., François, R., Frank, M., Jiang, G., Jones, J. L., Kooijman, E., Liu, Q., Lu, D., Pahnke, K., Ponzervera, E., Schmitt, M., Sun, X., Sutton, J. N., Thil, F., Weis, D., Wetzel, F., Zhang, A., and Zhang, J.: GEOTRACES Intercalibration of the Stable Isotope Composition of Dissolved Silicic Acid in Seawater, J. Anal. Atom. Spect., sumitted, 2016.

Grasshoff, K., Kremling, K., and Ehrhardt, M.: Methods of Seawater Analysis 3rd edition completely Revised and Extended edition, Wiley-VCH, ISBN 3-527-29589-5, 1999.

Hughes, H. J., Delvigne, C., Korntheuer, M., De Jong, J., André, L., and Cardinal, D.: Controlling the mass bias introduced by anionic and organic matrices in silicon isotopic measurements, J. Anal. Atom. Spectrom., 26, 1892-1896, 2011.

Jacquet, S. H. M., Dehairs, F., Lefèvre, D., Cavagna, A. J., Planchon, F., Christaki, U., Monin, L., André, L., Closset, I., and Cardinal, D.: Early spring mesopelagic carbon remineralization and transfer efficiency in the naturally iron-fertilized Kerguelen area, Biogeosciences, 12, 1713-1731, doi:10.5194/bg-12-1713-2015, 2015.

Karl, D. M. and Tien, G.: MAGIC: A sensitive and precise method for measuring dissolved phosphorus in aquatic environments, Limnol. Oceanogr., 37, 105-116, 1992.

Laurenceau-Cornec, E. C., Trull, T. W., Davies, D. M., Bray, S. G., Doran, J., Planchon, F., Carlotti, F., Jouandet, M.-P., Cavagna, A.-J., Waite, A. M., and Blain, S.: The relative importance of phytoplankton aggregates and zooplankton fecal pellets to carbon export: insights from free-drifting sediment trap deployments in naturally iron-fertilised waters near the Kerguelen Plateau, Biogeosciences, 12, 1007-1027, doi:10.5194/bg-121007-2015, 2015. 
Lasbleiz, M., Leblanc, K., Blain, S., Ras, J., Cornet-Barthaux, V., Hélias Nunige, S., and Quéguiner, B.: Pigments, elemental composition $(\mathrm{C}, \mathrm{N}, \mathrm{P}$, and $\mathrm{Si})$, and stoichiometry of particulate matter in the naturally iron fertilized region of Kerguelen in the Southern Ocean, Biogeosciences, 11, 5931-5955, doi:10.5194/bg-115931-2014, 2014.

Mongin, M., Molina, E., and Trull, T. W.: Seasonality and scale of the Kerguelen plateau phytoplankton bloom: A remote sensing and modeling analysis of the influence of natural iron fertilization in the Southern Ocean, Deep-Sea Res. Pt. II, 55, 880-892, 2008.

Mosseri, J., Quéguiner, B., Armand, L., and Cornet-Barthaux, V.: Impact of iron on silicon utilization by diatoms in the Southern Ocean: A case study of $\mathrm{Si} / \mathrm{N}$ cycle decoupling in a naturally ironenriched area, Deep-Sea Res. Pt. II, 55, 801-819, 2008.

Nelson, D. M., Brzezinski, M. A., Sigmon, D. E., and Franck, V. M.: A seasonal progression of Si limitation in the Pacific sector of the Southern Ocean, Deep-Sea Res. Pt. II, 48, 3973-3995, 2001.

Nelson, D. M., Anderson, R. F., Barber, R. T., Brzezinski, M. A., Buesseler, K. O., Chase, Z., Collier, R. W., Dickson, M.-L., François, R., Hiscock, M. R., Honjo, S., Marra, J., Martin, W. R., Sambrotto, R. N., Sayles, F. L., and Sigmon, D. E.: Vertical budgets for organic carbon and biogenic silica in the Pacific sector of the Southern Ocean, 1996-1998, Deep-Sea Res. Pt. II, 49, 1645-1674, 2002.

Opfergelt, S. and Delmelle, P.: silicon isotopes and continental weathering processes: Assessing controls on $\mathrm{Si}$ transfer to the ocean, C. R. Geosci., 344, 723-738, doi:10.1016/j.crte.2012.09.006, 2012.

Park, Y.-H., Fuda, J.-L., Durand, I., and Naveira Garabato, A. C.: Internal tides and vertical mixing over the Kerguelen Plateau, Deep-Sea Res. Pt. II, 55, 582-593, 2008 b.

Park, Y.-H., Durand, I., Kestenare, E., Rougier, G., Zhou, M., d'Ovidio, F., Cotté, C., and Lee, J.-H.: Polar Front around the Kerguelen Islands: An up-to-date determination and associated circulation of surface/subsurface water, J. Geophys. Res.Oceans, 119, 1-18, doi:10.1002/2014JC010061, 2014.

Parslow, J. S., Boyd, P. W., Rintoul, S. R., and Griffiths, F. B.: A persistent subsurface chlorophyll maximum in the Interpolar Frontal Zone south of Australia: Seasonal progression and implications for phytoplankton-light-nutrient interactions, J. Geophys. Res., 106, 31543-31557, 2001.

Planchon, F., Ballas, D., Cavagna, A.-J., Bowie, A. R., Davies, D., Trull, T., Laurenceau-Cornec, E. C., Van Der Merwe, P., and Dehairs, F.: Carbon export in the naturally iron-fertilized Kerguelen area of the Southern Ocean based on the ${ }^{234} \mathrm{Th}$ approach, Biogeosciences, 12, 3831-3848, doi:10.5194/bg-12-3831-2015, 2015

Pollard, R. T., Tréguer, P., and Read, J.: Quantifying nutrient supply to the Southern Ocean, J. Geophys. Res., 111, C05011, doi:10.1029/2005JC003076, 2006.

Pollard, R. T., Salter, I., Sanders, R. J., Lucas, M. I., Moore, C. M., Mills, R. A., Statham, P. J., Allen, J. T., Baker, A. R., Bakker, D. C. E., Charette, M. A., Fielding, S., Fones, G. R., French, M., Hickman, A. E., Holland, R. J., Hughes, J. A., Jickells, T. D., Lampitt, R. S., Morris, P. J., Nédélec, F. H., Nielsdóttir, M., Planquette, H., Popova, E. E., Poulton, A. J., Read, J. F., Seeyave, S., Smith, T., Stinchcombe, M., Taylor, S., Thomalla, S., Venables, H. J., Williamson, R., and Zubkov, M. V.: Southern Ocean deep-water carbon export enhanced by natural iron fertilization, Nature 457, 577-580, doi:10.1038/nature07716, 2009.

Pondaven, P., Ragueneau, O., Tréguer, P., Hauvespre, A., Dezileau, L., and Reyss, J. L.: Resolving the "opal paradox" in the Southern Ocean, Nature, 405, 168-172, 2000.

Quéroué, F., Sarthou, G., Planquette, H. F., Bucciarelli, E., Chever, F., van der Merwe, P., Lannuzel, D., Townsend, A. T., Cheize, M., Blain, S., d'Ovidio, F., and Bowie, A. R.: High variability in dissolved iron concentrations in the vicinity of the Kerguelen Islands (Southern Ocean), Biogeosciences, 12, 3869-3883, doi:10.5194/bg-12-3869-2015, 2015.

Ragueneau, O., Tréguer, P., Leynaert, A., Anderson, R. F., Brzezinski, M. A., DeMaster, D. J., Dugdale, R. C., Dymond, J., Fischer, G., François, R., Heinze, C., Maier-Reimer, E., Martin-Jézéquel, V., Nelson, D. M., and Quéguiner, B.: A review of the Si cycle in the modern ocean: recent progress and missing gaps in the application of biogenic opal as a paleoproductivity proxy, Global Planet. Change, 26, 317-365, 2000.

Ragueneau, O., Savoye, N., Del Amo, Y., Cotton, J., Tardiveau, B., and Leynaert, A.: A new method for the measurement of biogenic silica in suspended matter of coastal waters: using $\mathrm{Si}: \mathrm{Al}$ ratios to correct for the mineral interference, Cont. Shelf Res., 25, 697710, 2005.

Rembauville, M., Blain, S., Armand, L., Quéguiner, B., and Salter, I.: Export fluxes in a naturally iron-fertilized area of the Southern Ocean - Part 2: Importance of diatom resting spores and faecal pellets for export, Biogeosciences, 12, 3171-3195, doi:10.5194/bg-12-3171-2015, 2015.

Rembauville, M., Blain, S., Caparros, J., and Salter, I.: Particulate matter stoichiometry driven by microplankton community structure in summer in the Indian sector of the Southern Ocean, Limnol. Oceanogr., 61, 1301-1321, doi:10.1002/lno.10291, 2016.

Reynolds, B. C., Frank, M., and Halliday, A. N.: Silicon isotope fractionation during nutrient utilization in the North Pacific, Earth Planet. Sci. Lett., 244, 431-443, 2006.

Reynolds, B. C., Aggarwal, J., André, L., Baxter, D., Beucher, C., Brzezinski, M. A., Engström, E., Georg, R. B., Land, M., Leng, M. J., Opfergelt, S., Rodushkin, I., Sloane, H. J., van den Boorn, S. H. J. M., Vroon, P. Z., and Cardinal, D.: An inter-laboratory comparison of $\mathrm{Si}$ isotope reference materials, J. Anal. Atom. Spectrom., 22, 561-568, doi:10.1039/b616755a, 2007.

Sanial, V., van Beek, P., Lansard, B., Souhaut, M., Kestenare, E., d'Ovidio, F., Zhou, M., and Blain, S.: Use of Ra isotopes to deduce rapid transfer of sediment-derived inputs off Kerguelen, Biogeosciences, 12, 1415-1430, doi:10.5194/bg-12-1415-2015, 2015.

Sarmiento, J. L., Gurber, N., Brzezinski, M. A., and Dunne, J. P.: High-latitude controls of thermocline nutrients and low latitude biological productivity, Nature, 427, 56-60, 2004.

Sutton, J. N., Varela, D. E., Brzezinski, M. A., and Beucher, C. P.: Species-dependent silicon isotope fractionation by marine diatoms, Geochim. Cosmochim. Ac., 104, 300-309, 2013.

Takahashi, T., Sutherland, S. C., Wanninkhof, R., Sweeney, C., Feely, R. A., Chipman, D. W., Hales, B., Friederich, G., Chavez, F., Sabine, C., Watson, A., Bakker, D. C. E., Schuster, U., Metzl, N., Yoshikawa-Inoue, H., Ishii, M., Midorikawa, T., Nojiri, Y., Körtzinger, A., Steinhoff, T., Hoppema, M., Olafsson, J., Arnarson, T. S., Tilbrook, B., Johannessen, T., Olsen, A., Bellerby, R., Wong, C. S., Delille, B., Bates, N. R., and de Baar, H. J. W.: Cli- 
matological mean and decadal change in surface ocean $p \mathrm{CO}_{2}$, and net sea-air $\mathrm{CO}_{2}$ flux over the global oceans, Deep-Sea Res. Pt. II, 56, 554-577, doi:10.1016/j.dsr2.2008.12.009, 2009.

Tréguer, P. J. and De La Rocha, C. L.: The World Ocean Silica Cycle, Annu. Rev. Mar. Sci., 5, 477-501, 2013.

Trull, T., Rintoul, S. R., Hadfield, M., and Abraham, E. R.: Circulation and seasonal evolution of polar waters south of Australia: Implications for iron fertilization of the Southern Ocean, DeepSea Res. Pt. II, 48, 2439-2466, 2001.

Trull, T. W., Davies, D. M., Dehairs, F., Cavagna, A.-J., Lasbleiz, M., Laurenceau-Cornec, E. C., d'Ovidio, F., Planchon, F., Leblanc, K., Quéguiner, B., and Blain, S.: Chemometric perspectives on plankton community responses to natural iron fertilisation over and downstream of the Kerguelen Plateau in the Southern Ocean, Biogeosciences, 12, 1029-1056, doi:10.5194/bg-121029-2015, 2015.

Uitz, J., Claustre, H., Griffiths, F. B., Ras, J., Garcia, N., and Sandroni, V.: A phytoplankton class-specific primary production model applied to the Kerguelen Islands region (Southern Ocean), Deep-Sea Res. Pt. I, 56, 541-560, 2009.
Van den Boorn, S. H. J. M., Vroon, P. Z., and Van Bergen, M. J.: Sulfur-induced offsets in MC-ICP-MS silicon-isotope measurements, J. Anal. Atom. Spectrom., 24, 1111-1114, 2009.

Varela, D. E., Pride, C. J., and Brzezinski, M. A.: Biological fractionation of silicon isotopes in Southern Ocean surface waters, Global Biogeochem. Cy., 18, GB1047, doi:10.1029/2003GB002140, 2004.

Wetzel, F., de Souza, G. F., and Reynolds, B. C.: What controls silicon isotope fractionation during dissolution of diatom opal?, Geochim. Cosmochim. Ac., 131, 128-137, doi:10.1016/j.gca.2014.01.028, 2014.

Zhou, M., Zhu, Y., d'Ovidio, F., Park, Y.-H., Durand, I., Kestenare, E., Sanial, V., Van-Beek, P., Queguiner, B., Carlotti, F., and Blain, S.: Surface currents and upwelling in Kerguelen Plateau regions, Biogeosciences Discuss., 11, 6845-6876, doi:10.5194/bgd-116845-2014, 2014. 